\title{
The wildland fire emission inventory: western United States emission estimates and an evaluation of uncertainty
}

\author{
S. P. Urbanski, W. M. Hao, and B. Nordgren \\ Missoula Fire Sciences Laboratory, Rocky Mountain Research Station, United States Forest Service, \\ Missoula, Montana, USA
}

Received: 11 August 2011 - Published in Atmos. Chem. Phys. Discuss.: 18 August 2011

Revised: 6 December 2011 - Accepted: 7 December 2011 - Published: 20 December 2011

\begin{abstract}
Biomass burning emission inventories serve as critical input for atmospheric chemical transport models that are used to understand the role of biomass fires in the chemical composition of the atmosphere, air quality, and the climate system. Significant progress has been achieved in the development of regional and global biomass burning emission inventories over the past decade using satellite remote sensing technology for fire detection and burned area mapping. However, agreement among biomass burning emission inventories is frequently poor. Furthermore, the uncertainties of the emission estimates are typically not well characterized, particularly at the spatio-temporal scales pertinent to regional air quality modeling. We present the Wildland Fire Emission Inventory (WFEI), a high resolution model for non-agricultural open biomass burning (hereafter referred to as wildland fires, WF) in the contiguous United States (CONUS). The model combines observations from the MODerate Resolution Imaging Spectroradiometer (MODIS) sensors on the Terra and Aqua satellites, meteorological analyses, fuel loading maps, an emission factor database, and fuel condition and fuel consumption models to estimate emissions from WF.

WFEI was used to estimate emissions of $\mathrm{CO}$ (ECO) and $\mathrm{PM}_{2.5}\left(\mathrm{EPM}_{2.5}\right)$ for the western United States from 2003 2008. The uncertainties in the inventory estimates of ECO and $\mathrm{EPM}_{2.5}\left(u_{\mathrm{ECO}}\right.$ and $u_{\mathrm{EPM}_{2.5}}$, respectively) have been explored across spatial and temporal scales relevant to regional and global modeling applications. In order to evaluate the uncertainty in our emission estimates across multiple scales we used a figure of merit, the half mass uncertainty, $\tilde{u}_{\mathrm{EX}}$ (where $\mathrm{X}=\mathrm{CO}$ or $\mathrm{PM}_{2.5}$ ), defined such that for a given aggregation level $50 \%$ of total emissions occurred from elements
\end{abstract}

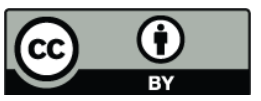

Correspondence to: S. P. Urbanski (surbanski@fs.fed.us) with $u_{\mathrm{EX}}<\tilde{u}_{\mathrm{EX}}$. The sensitivity of the WFEI estimates of $\mathrm{ECO}$ and $\mathrm{EPM}_{2.5}$ to uncertainties in mapped fuel loading, fuel consumption, burned area and emission factors have also been examined.

The estimated annual, domain wide ECO ranged from $436 \mathrm{Gg} \mathrm{yr}^{-1}$ in 2004 to $3107 \mathrm{Gg} \mathrm{yr}^{-1}$ in 2007 . The extremes in estimated annual, domain wide $\mathrm{EPM}_{2.5}$ were $65 \mathrm{Gg} \mathrm{yr}^{-1}$ in 2004 and $454 \mathrm{Gg} \mathrm{yr}^{-1}$ in 2007. Annual WF emissions were a significant share of total emissions from non-WF sources (agriculture, dust, non-WF fire, fuel combustion, industrial processes, transportation, solvent, and miscellaneous) in the western United States as estimated in a national emission inventory. In the peak fire year of 2007, WF emissions were $\sim 20 \%$ of total (WF + non-WF) CO emissions and $\sim 39 \%$ of total $\mathrm{PM}_{2.5}$ emissions. During the months with the greatest fire activity, WF accounted for the majority of total $\mathrm{CO}$ and $\mathrm{PM}_{2.5}$ emitted across the study region. Uncertainties in annual, domain wide emissions was $28 \%$ to $51 \%$ for $\mathrm{CO}$ and $40 \%$ to $65 \%$ for $\mathrm{PM}_{2.5}$. Sensitivity of $\tilde{u}_{\mathrm{ECO}}$ and $\tilde{u}_{\mathrm{EPM}_{2.5}}$ to the emission model components depended on scale. At scales relevant to regional modeling applications ( $\Delta x=10 \mathrm{~km}, \Delta t=1$ day) WFEI estimates $50 \%$ of total ECO with an uncertainty $<133 \%$ and half of total $\mathrm{EPM}_{2.5}$ with an uncertainty $<146 \%$. $\quad \tilde{u}_{\mathrm{ECO}}$ and $\tilde{u}_{\mathrm{EPM}_{2.5}}$ are reduced by more than half at the scale of global modeling applications ( $\Delta x=100 \mathrm{~km}, \Delta t=30$ day) where $50 \%$ of total emissions are estimated with an uncertainty $<50 \%$ for $\mathrm{CO}$ and $<64 \%$ for $\mathrm{PM}_{2.5}$. Uncertainties in the estimates of burned area drives the emission uncertainties at regional scales. At global scales $\tilde{u}_{\mathrm{ECO}}$ is most sensitive to uncertainties in the fuel load consumed while the uncertainty in the emission factor for

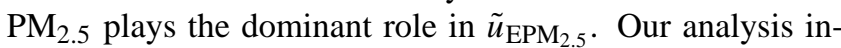
dicates that the large scale aggregate uncertainties (e.g. the uncertainty in annual CO emitted for CONUS) typically reported for biomass burning emission inventories may not be appropriate for evaluating and interpreting results of regional

Published by Copernicus Publications on behalf of the European Geosciences Union. 
scale modeling applications that employ the emission estimates. When feasible, biomass burning emission inventories should be evaluated and reported across the scales for which they are intended to be used.

\section{Introduction}

Biomass burning (BB; defined here as open biomass burning which includes wildfires and managed fires in forests, savannas, grasslands, and shrublands, and agricultural fire such the burning of crop residue) is a significant source of global trace gases and particles (van der Werf et al., 2010; Michel et al., 2005; Ito and Penner, 2004). Biomass fire emissions comprise a substantial component of the total global source of carbon monoxide ( $40 \%)$, carbonaceous aerosol (35\%), and nitrogen oxides (20\%) (Langmann et al., 2009). Other primary BB emissions include greenhouse gases $\left(\mathrm{CO}_{2}\right.$, $\mathrm{CH}_{4}, \mathrm{~N}_{2} \mathrm{O}$ ) and a vast array of photochemically reactive nonmethane organic compounds (NMOC; Akagi et al., 2011) that contribute to the production of ozone $\left(\mathrm{O}_{3}\right)$ and secondary organic aerosol (Alvarado et al., 2009; Pfister et al., 2008; Sudo and Akimoto, 2007).

$\mathrm{BB}$ emissions have a significant influence on the chemical composition of the atmosphere, air quality, and the climate system (Langmann et al., 2009; Lapina et al., 2006; Simpson et al., 2006). Fires influence climate through the production of long-lived greenhouse gases and short-lived climate forcers (e.g. aerosol, $\mathrm{O}_{3}$ ) which are agents for direct and indirect (e.g. aerosols cloud effects) climate forcing. Biomass fires contribute to air quality degradation by increasing the levels of pollutants that are detrimental to human health and ecosystems, and that decrease visibility (Liu et al., 2009; Park et al., 2007). The air quality impacts occur through the emission of primary pollutants (e.g. fine particulate matter; $\mathrm{PM}_{2.5}$ ) and production of secondary pollutants (e.g. $\mathrm{O}_{3}$ and secondary organic aerosol) when NMOC and nitrogen oxides released by biomass fires undergo photochemical processing. Air quality can be impacted by the transport and transformation of BB emissions on local (Muhle et al., 2007; Phuleria et al., 2005), regional (Spracklen et al., 2007; Sapkota et al., 2005; DeBell et al., 2004), and continental (Morris et al., 2006) scales.

BB emission inventories (EI) serve as critical input for atmospheric chemical transport models that are used to understand the role of biomass fires in the atmosphere and climate. BB EI are also important for interpreting in-situ and remote atmospheric observations. The application determines the requirements of a specific BB EI, such as spatial and temporal resolution and chemical speciation. Modeling of regional air quality needs high resolution $\mathrm{EI}(\Delta x \lesssim 25 \mathrm{~km}, \Delta t \leq 1$ day), while global modeling applications can use less resolved input ( $\Delta x=0.5$ to 3 degree, $\Delta t=$ week to month).
Many BB emission models and inventories have been developed to provide input for a range of modeling applications. Case study EI have been assembled to assess the impact of specific fire events on air quality (e.g., the October 2003 wildfire outbreak in southern California, USA, Mühle et al., 2007; Clinton et al., 2006; and prescribed burns in Georgia, Liu et al., 2009). Emission models to support the simulation of cumulative smoke impacts from fires have been implemented for the contiguous United States (CONUS; Larkin et al., 2009; Zhang et al., 2008) and North America (Wiedinmyer et al., 2006). These models are designed to provide near-real-time fire emission estimates for air quality forecasts. Other region specific BB EI have covered boreal Siberia (1998-2002; Soja et al., 2004), Africa (2000-2007; Liousse et al., 2010), and tropical Asia (20002006; Chang and Song, 2010).

Several global BB EI have been produced in the last decade. The spatial and temporal resolution, speciation, and coverage period of the inventories varies considerably. Ito and Penner (2004) and Hoelzemann et al. (2004) published global, monthly EI for 2000 at spatial resolutions of $1 \mathrm{~km}$ and 0.5 degree, respectively. The Global Fire Emissions Database (GFED, van der Werf et al., 2010; van der Werf et al., 2006), a widely used BB inventory, is available over $1997-2009$ as 8-day and monthly composites at $0.5^{\circ}$ or $1.0^{\circ}$ spatial resolution. Mieville et al. (2010) recently produced a monthly, $1 \mathrm{~km}$ spatial resolution global emission dataset for 1997-2005 and used this contemporary inventory to reconstruct historical (1900-2000) emissions. The Fire Locating and Modeling of Burning Emissions (FLAMBE) program estimates near-real-time global BB emissions to support operational aerosol forecasting (Reid et al., 2009). The FLAMBE archive provides emissions datasets from 2000 to the present. The most recent addition to global BB EI category was the Fire Inventory from NCAR (FINN), a global, high resolution BB emission model that is capable of supporting near-realtime applications (Wiedinmyer et al., 2011). A unique aspect of FINN is that it provides a comprehensive inventory of NMOC emissions allocated as lumped species for widely used atmospheric chemical mechanisms. FINN emission estimates are available for 2005-2010 with daily, $1 \mathrm{~km}$ resolution.

While significant progress has been achieved in the development of methods for estimating $\mathrm{BB}$ emissions, agreement among BB EI is variable. For example, GFED v3 and FINN v1 showed excellent agreement in annual, global $\mathrm{CO}_{2}, \mathrm{CO}$, and $\mathrm{CH}_{4}$ emissions over 2005-2009, the inventories agreed within 3-35\% for each compound (Wiedinmyer et al., 2011; van der Werf et al., 2010). In contrast, Stroppiana et al. (2010) compared five global BB EI (including GFED v3) for the year 2003 and found that total CO emissions differed by a factor of 3.9 (high/low). The authors cited differences in the area affected by fires and vegetation characteristics as the prime causes for variability among inventories. On a continental basis, the disagreement in annual 
emission estimates among various inventories can be much greater. While 2003 total CO emissions for Africa varied by a factor of 2.2, those for North America varied by a factor of 14.5 (Stroppiana et al., 2010). Other inventories showed somewhat better agreement; for example, annual CO emissions estimated for North America by GFED v3 (van der Werf et al., 2010) and a continental BB EI (Wiedinmyer et al., 2006) differed by a factor of 1.15 to 1.93 over 20022004. Over shorter time periods, the disagreement between BB EI is more significant. Year 2003 monthly CO emissions for Africa from six different inventories varied by a factor of 7 over the year, with maximum differences of 300-400\% during the peak emission months (Liousse et al., 2010). Similarly, Al-Saadi et al. (2008) compared four satellite-driven BB emission models over March 2006 to September 2006 and found that the estimates of monthly $\mathrm{CO}$ emissions integrated over CONUS varied by an order of magnitude.

The lack of consistency among emission inventories and the absence of information regarding uncertainty at pertinent scales makes it difficult to determine which BB EI is most appropriate for a particular application and hinders the evaluation of model results. For example, the annual, continental scale uncertainty reported for a BB EI may seriously misrepresent the relevant uncertainty for an air quality simulation conducted with horizontal grid spacing of $10 \mathrm{~km}$. This is particularly true given that $\mathrm{BB}$ emissions typically have large spatio-temporal gradients. Further, the sensitivity of the emission estimates to the model components is generally not well characterized. Understanding the sensitivity of emission estimates to assumptions and uncertainties associated with each input to the emission model - burned area, fuel map, fuel load, fuel consumption, and emission factors, is crucial for properly assessing the impact these assumptions may have on atmospheric chemical transport model simulations.

We present the Wildland Fire Emission Inventory (WFEI), a high resolution ( $500 \mathrm{~m}, 1$ day) wildland fire emission model designed to support regional scale atmospheric chemistry studies and air quality forecasting. In this paper, wildland fire (WF) refers to non-agricultural, open biomass burning which differs from the more commonly used definition of open BB which usually includes agricultural burning (e.g. pasture maintenance and crop residue). WFEI was used to estimate WF emissions of $\mathrm{CO}(\mathrm{ECO})$ and $\mathrm{PM}_{2.5}\left(\mathrm{EPM}_{2.5}\right)$ for the western United States from 2003-2008. We introduce a figure of merit, the half mass uncertainty, to evaluate uncertainty in the EI across spatio-temporal scales. To evaluate the dependence of the model's uncertainty to scale, the base resolution (500 $\mathrm{m}$ and 1 day) emission inventory was aggregated across multiple spatial grids $(\Delta x=10,25,50,100,200 \mathrm{~km})$ and time steps ( $\Delta t=1,5,10,30,365$ day). The spatial and temporal sensitivity of WFEI estimates of ECO and EPM 2.5 to uncertainties in mapped fuel loading, fuel consumption, burned area and emission factors is also examined. This assessment may be the first study which has attempted to rigor- ously evaluate the uncertainties of a BB EI across a range of spatial and temporal scales. WFEI was designed for the contiguous United States and here it is applied to western United States over 2003-2008. However, the uncertainty/sensitivity analysis presented here may be applicable to BB EI for different regions of the globe.

\section{Methodology}

\subsection{Biomass burning emission model}

Biomass burning emission (E) of a compound (i) may be estimated as the product of area burned $\left(\mathrm{A} ; \mathrm{km}^{2}\right)$, fuel load consumed (FLC; kg-dry vegetation $\mathrm{km}^{-2}$ ), and specific emission factors (EF; [g-compound $i]$ [kg-dry vegetation $\left.{ }^{-1}\right]$ ) (Langmann et al., 2009; Seiler and Crutzen, 1980):

$E(k, t, i)=A(k, t) \times \mathrm{FLC}(k, t) \times 0.001 \times \mathrm{EF}(k, t)$

where, $k$ is location, $t$ is time, $i$ is species and FLC is the product of the fuel loading (FL; $\mathrm{kg}$-dry vegetation $\mathrm{km}^{-2}$ ) and combustion completeness ( $\mathrm{C}$, dimensionless). Emission factors are traditionally reported in units of $\mathrm{g} \mathrm{kg}^{-1}$ and the factor of 0.001 in Eq. (1) converts the EF units into $\mathrm{kg} \mathrm{kg}^{-1}$. Equation (1) is the basis of WFEI which provides daily emission inventories with a spatial resolution of $500 \mathrm{~m}$. WFEI was originally designed to provide near-real-time WF emissions for assimilation into air quality forecasting systems. The model combines observations from the MODerate Resolution Imaging Spectroradiometers (MODIS) on NASA's Terra and Aqua satellites, meteorological analyses, fuel loading maps, an emission factor database, and fuel condition and fuel consumption models. We describe WFEI as applied to the western United States in the following sections.

\subsubsection{MODIS based burned area}

Burned area was mapped using an improved version of the MODIS - direct broadcast (DB) algorithm developed by Urbanski et al. (2009a). Here we provide a brief overview of the algorithm and describe algorithm improvements and the MODIS data processed in this study. Details of the algorithm, a thorough evaluation of the algorithm, and a discussion of the deficiencies and limitations of burned area mapping using remote sensing and ground-based information are provided in Urbanski et al. (2009a) and references therein.

The MODIS algorithm combines active fire detections and single satellite scene burn scar detections to map burned area with a nominal spatial and temporal resolution of $500 \mathrm{~m}$ and 1 day. The MODIS-DB algorithm provides rapid mapping of burned area and enables production of a regional emission inventory within $1 \mathrm{~h}$ of the final (Aqua), local MODIS overpass. While the algorithm was designed to process DB data in near-real-time, archived data may also be used. This study used MODIS Level-1B, Collection 5 Terra and Aqua 
datasets obtained from the NASA MODIS L1 and Atmosphere Archive and Distribution System (NASA, 2011) to identify burn scars. Collection 5 of the standard MXD14 product (Giglio et al., 2003) provided active fire detections (spatial resolution $1 \mathrm{~km}$ ). The burn scar algorithm (Urbanski et al., 2009a; Li et al., 2004) was applied to the Level-1B datasets to identify potentially burned pixels - provisional burn scar detections (spatial resolution $500 \mathrm{~m}$ ). The purpose of the algorithm is to map WF burned area; therefore the active fire and burn scar detections were filtered using an agricultural land mask (Sect. 2.1.2) to eliminate burning due to agricultural activity. The processed data was aggregated temporally according to the date (Local Time) of satellite acquisition. Provisional burn scars were then screened for false detections using a contextual filter which eliminates pixels not proximate to a recent active fire detection. To be classified as "confirmed", provisional burn scar detections were required to be within $3 \mathrm{~km}$ of any active fire detection from the preceding 5 days. A daily burned area product was created by resampling pixel centers of confirmed burn scar detections onto a $500 \mathrm{~m} \times 500 \mathrm{~m}$ CONUS grid using a nearest neighbor approach. The burned area grid for each day was compared against a cumulative burned area grid which tracked the burned area for 90 days. Comparison against the cumulative burned area grid identified grid cells newly burned in the preceding day, providing a map of burned area growth for that day.

The burned area mapping employed in this study was improved over that reported in Urbanski et al. (2009a) through the two modifications. First, the contextual filter for burn scar detection was changed to $3 \mathrm{~km}$ and 5 days in the improved implementation versus $5 \mathrm{~km}$ and 10 days in the original version. Second, in the current study, active fire detections were used only to confirm burn scar detections. Previously, active fire detections were used to identify burned grid cells in addition to confirming burn scars. These improvements were proposed in Urbanski et al. (2009a) and their implementation has largely eliminated the overestimation of burned area in the original mapping scheme. The previous algorithm has a bias of $36 \%$ (Urbanski et al., 2009a) while the bias of the improved algorithm used in this study is $7 \%$ (Sect. 2.2.3). An evaluation of the improved burned area mapping algorithm used in this study is provided in Appendix A.

\subsubsection{Fuel map and fuel loading}

The biomass, i.e. fuel loading (FL; $\mathrm{kg}$ dry vegetation $\mathrm{km}^{-2}$ ), was estimated using wildland fuel loading models. A fuel loading model describes and classifies fuelbed physical characteristics to provide numerical input for fire effects models (Sect. 2.1.4). In this study the fire effects models CONSUME (Prichard et al., 2006) and FOFEM (Reinhardt, 2003) were used to estimate the consumption of duff, litter, dead wood, herbaceous vegetation, and shrubs (Sect. 2.1.4). The Fuel Loading Models (FLM; Lutes et al., 2009) and the
Fuel Characteristics Classification System (FCCS; Ottmar, et al., 2007a) were the fuel loading models used in this study. We selected these fuel loading models because they were mapped by the LANDFIRE project (LANDFIRE, 2011a, b) and they provide a full description of the dead wood and duff fuel strata that dominate loading, and hence potential emissions, in forested ecosystems of the western United States. WFEI incorporates only surface fuels and, for reasons discussed below, does not include canopy fuels.

The FCCS is a tool to classify fuelbeds according to their potential fire behavior and fuel consumption (Ottmar et al., 2007a). The FCCS contains over 200 fuelbeds for the United States, organized by to vegetation type (e.g. Interior Ponderosa Pine - Douglas-fir Forest). The fuelbeds were developed using a wide range of sources: scientific literature, fuels photo series, fuel data sets, and expert opinion (Ottmar et al., 2007a).

The FLM are a surface fuel classification that categorizes fuelbeds according to potential fire effects (consumption, emissions, soil surface temperature; Lutes et al., 2009). The FLM were developed using an extensive database of surface fuel measurements from 4046 forested plots from across the contiguous United States. The FLM contains 21 fuel classes developed using a classification tree analysis to estimate the critical loads of duff, litter, fine woody debris, and coarse woody debris associated with 10 unique fire effects regimes. The 10 unique fire effects regimes were identified by clustering the potential fire effects of each measurement plot as simulated using FOFEM (Lutes et al., 2009).

The major differences between the FCCS and FLM are:

1. The models were developed using different philosophies to classify fuelbeds; the FCCS fuelbeds are formally classified according to vegetation type while the FLM fuelbeds are categorized based on the anticipated fire effects of the fuel loadings.

2. The FLM covers only forests, while the FCCS includes fuelbeds for herbaceous and shrubland cover types. The absence of FLMs for non-forest cover types required the development of supplemental fuelbeds as part of our study (see below).

3. Due to a lack of data that satisfied their study's criteria, the FLM provides only a cursory treatment of understory herbs and shrubs. Because many of the plots in the FLM dataset (2707 of 4046) were missing herbaceous or shrub loadings, all of the FLM were assigned same loading, the dataset median, for these components. The FCCS provides specific herbaceous and shrub fuel loadings for each vegetation type classified.

4. The FLM were developed from a large, uniform collection of surface fuel measurements. In contrast, the FCCS were developed using a diverse range of data sources and the nature of the underlying data is variable across fuelbeds. 
The original FLM classifies only forests and does not provide models for herbaceous or shrub fuelbeds that are important over large swaths of the western United States (e.g. sage brush and chaparral). A field guide for identifying FLMs does include models for sagebrush and chaparral (Sikkink et al., 2009) and the LANDFIRE mapping of the FLMs included these non-forested models. However, we chose not to use the Sikkink et al. (2009) fuel loads and instead opted to develop our own fuel loadings for non-forested classes of the LANDFIRE FLM map. Using the Natural Fuels Photo Series (Natural Fuels Photo Series, 2011) we developed six non-forest cover type fuel loading models: grass, sage brush, shrubs, coastal sage shrub, chamise, and ceanothus mixed chaparral. We refer to these six fuel loading models as the "FLM supplemental models". The photo series datasets and methods used to develop the FLM supplemental models are described in Appendix B.

Our study used the LANDFIRE FLM and FCCS spatial data layers (LANDFIRE, 2011b) to quantify surface fuels. The LANDFIRE spatial data layers are provided as $30 \mathrm{~m}$ resolution rasters which we aggregated to $500 \mathrm{~m}$ resolution using majority resampling to match the resolution of our daily burned area product (Sect. 2.1.1). FLM and FCCS fuel codes were assigned to each burned grid cell by extracting the FLM and FCCS values from the $500 \mathrm{~m}$ rasters at the center point of each burned grid cell. Approximately $39 \%$ of the fire impacted FLM pixels were non-forest and these FLM pixels were re-coded with the FCCS codes of those pixels. The re-coded pixels were then assigned a FLM supplemental model based on the vegetation type of the FCCS fuelbed (Appendix B).

Our study did not include forest canopy fuels because the methods used in this study could not identify the occurrence of crown fire or reliably model canopy fuel consumption. While our burned area mapping technique efficiently identifies burned pixels, it does not provide information regarding the occurrence of crown fire. The fuel consumption models used in this study (CONSUME and FOFEM) do not include empirical or physical process based modeling of canopy consumption. Additionally, the FLM do not include canopy fuel loading and augmentation of the FLM with canopy fuel loading estimates would have been problematic given the manner in which the FLMs were developed - classification by anticipated fire effects not vegetation type. Given these limitations, we chose to exclude canopy fuel consumption from our primary analysis. However, a rough estimate of canopy consumption and resultant emissions using the FCCS is provided in Appendix C.

\subsubsection{Fuel conditions}

Fuel moistures for dead and live fuels were calculated using the National Fire Danger Rating System (NFDRS) basic equations (Cohen and Deeming, 1985). The NFDRS provides fuel moisture models for live (woody shrubs and herbaceous plants) and dead fuels. Dead fuels are classified by timelag intervals (the e-folding time for a fuel particle's moisture content to return to equilibrium with its local environment) which are proportional to the diameter of fuel particle (twig, branch, or log). The NFDRS classifies 1-h, 10-h, 100-h, and 1000-h dead fuels corresponding to diameters of $<0.64,0.64-2.54,2.54-7.62,>7.62 \mathrm{~cm}$. 1-h and 10-h dead fuel moistures were calculated from the hourly air temperature $(T)$, relative humidity $(\mathrm{RH})$, and surface solar radiation (SRAD) following the NFDRS implementation of Carlson et al. (2002). The meteorological input for the fuel moisture calculations was obtained from the North American Regional Reanalysis (NARR) meteorological fields ( $32 \mathrm{~km}$ horizontal resolution, 45 vertical layers, and a $3 \mathrm{~h}$ output) (Mesinger et al., 2006). $T, \mathrm{RH}$, and SRAD were estimated for the hours between analyses by interpolating the 3-h NARR output. The NFDRS does not include equations for duff moisture, which is needed to predict duff consumption and is required input for both CONSUME and FOFEM. The closed canopy empirical relationship of Harrington (1982) was used to estimate the duff moisture from the NFDRS 100-h fuel moisture. The Harrington (1982) study was limited to Ponderosa Pine forests and likely does not provide the best estimate of duff moisture for all forest ecosystems in the western United States. However, using the same methods to estimate fuel moistures for all cover types avoids introducing additional variability into our analysis that would have interfered with our ability to assess uncertainties associated with the fuel consumption models, a key objective of this study.

\subsubsection{Fuel consumption}

Factors controlling fire behavior and the consumption of wildland fuels include fuelbed type, fuel arrangement, fuel condition (moisture, soundness of dead wood) and meteorology (Anderson, 1983; Albini, 1976; Rothermel, 1972). Our study used two fire effects models, CONSUME and FOFEM, to simulate fuel consumption. While the models require similar input, fuel loading by fuel class (with slightly different size classifications for woody fuels) and fuel moisture, they employ significantly different approaches towards predicting surface fuel consumption (dead wood and litter). While both models were calibrated using field measurements of fuel consumption from WFs, neither model has been extensively validated using independent data from wildfires or prescribed fires. Next we provide a brief description of the models.

CONSUME is an empirical fire effects model that predicts fuel consumption by fire phase (flaming, smoldering, residual smoldering), heat release, and pollutant emissions (Prichard et al., 2006). The CONSUME natural fuels algorithms include predictive equations for the consumption of shrubs, herbaceous vegetation, dead woody fuels, litterlichen-moss, and duff. The dead woody fuels algorithms are comprised of equations for different size classes and decay status (sound or rotten). There are specific equations for dead 
Table 1. Probability distribution functions and parameters used in the Monte Carlo analysis.

\begin{tabular}{|c|c|c|}
\hline Model component & pdf & Parameters \\
\hline $\begin{array}{l}\text { A } \\
\left(\mathrm{km}^{2}\right)\end{array}$ & Normal & $\mu_{A}=\mathrm{A}, \sigma_{A}=(5.03 \mathrm{~A})^{1 / 2}$ \\
\hline $\begin{array}{l}\text { FLC } \\
\text { (kg-dry } \\
\text { vegetation } \\
\text { burned } \mathrm{km}^{-2} \text { ) }\end{array}$ & Normal & $\begin{aligned} \mu_{\mathrm{FLC}}(\mathrm{k}, \mathrm{t})= & \frac{\sum_{j=1}^{4} \operatorname{FLC}(j, k, t)}{4} \\
\sigma_{\mathrm{FLC}}(k, t)= & \\
& 0.5 \times(\max (\operatorname{FLC}(k, t)) \\
& -\min (\operatorname{FLC}(k, t)))\end{aligned}$ \\
\hline $\begin{array}{l}\text { EFCO } \\
(\mathrm{g} \mathrm{CO} \mathrm{kg} \mathrm{-} \mathrm{dry} \\
\left.\text { vegetation burned }^{-1}\right)\end{array}$ & $\begin{array}{l}\text { Normal } \\
\text { Log-normal }\end{array}$ & $\begin{array}{l}\text { Forest: } \mu_{\mathrm{EFCO}}=87.0, \\
\sigma_{\mathrm{EFCO}}=17.9 \\
\text { Non-forest: } \mu_{\mathrm{EFCO}}=4.21 \text {, } \\
\sigma_{\mathrm{EFCO}}=0.30\end{array}$ \\
\hline $\begin{array}{l}\mathrm{EFPM}_{2.5} \\
\left(\mathrm{~g} \mathrm{PM}_{2.5} \mathrm{~kg}-\text { dry }\right. \\
\text { vegetation burned }\end{array}$ & $\begin{array}{l}\text { Log-normal } \\
\text { Log-normal }\end{array}$ & $\begin{array}{l}\text { Forest: } \mu_{\mathrm{EFPM}_{2.5}}=2.59, \\
\sigma_{\mathrm{EFPM}_{2.5}}=0.34 \\
\text { Non-forest: } \mu_{\mathrm{EFPM}_{2.5}}=2.20 \text {, } \\
\sigma_{\mathrm{EFPM}_{2.5}}=0.47\end{array}$ \\
\hline
\end{tabular}

wood and duff consumption in the western United States. Fuel moisture is the independent variable in all of the natural fuel equations except for the shrub, herbaceous vegetation, litter-lichen-moss, and 1-hour size class dead wood (diameter $<0.64 \mathrm{~cm})$ strata.

FOFEM, the First Order Fire Effects Model, simulates fuel consumption, smoke emissions, mineral soil exposure, soil heating, and tree mortality (Reinhardt 2003). FOFEM employs BURNUP (Albini et al., 1995), a physical model of heat transfer and burning rate, to calculate the consumption and heat release of dead woody fuels and litter. Duff consumption is calculated using the empirical equations of Brown et al. (1985). The consumption of herbaceous fuels and shrubs are estimated using rules of thumb (FOFEM 5.7, 2011). In addition to loading by fuel class, FOFEM requires fuel moisture (10-hr, 1000-hr, and duff) as input.

\subsubsection{Fuel load consumed}

The combination of fuel loading maps (FLM, FCCS) and consumption models (FOFEM, CONSUME) provided four predictions of fuel load consumption, FLC:

$\mathrm{FLC}_{i, j}=\mathrm{FL}_{i} \times C_{j}$

where FL is the fuel loading (FL; kg-dry vegetation $\mathrm{km}^{-2}$ ), $C$ is the consumption completeness, and FLC is the dry mass of vegetation burned per $\mathrm{km}^{2}$. In Eq. (2) the $i$ and $j$ index identify the fuel loading model (FLM or FCCS) and fuel consumption model (FOFEM or CONSUME), respectively ( $\mathrm{FL}_{1}$ $=$ FLM, $\mathrm{FL}_{2}=$ FCCS,$C_{1}=$ FOFEM, $C_{2}=$ CONSUME). The mean of the four predictions was used as the best estimate of FLC $\left(\mu_{\text {FLC }}\right.$, Table 1$)$ fuel load consumed (FLC).

\subsubsection{Emission factors}

An emission factor (EF) provides the mass of a compound emitted per mass of dry fuel consumed. Our study developed "best estimate" $\mathrm{CO}$ and $\mathrm{PM}_{2.5}$ EFs for burning in forest and non-forest (grasslands and shrublands) cover types from data reported in the literature. The literature values used were fireaverage EF measured for wildfires and prescribed fires in the United States and southwestern Canada. The EF source studies were all based on in-situ emission measurements obtained from near source airborne or ground based tower measurements. The published EFs were used to derive probability distribution functions (pdf) for EFCO and EFPM 2.5 that were used in our uncertainty analysis (Sect. 2.2.5). The statistical variability of each $\mathrm{EF}$ (CO or $\mathrm{PM}_{2.5}$, forest or non-forest) was determined by fitting log-normal and normal distributions to the source data. For each EF, the $\mu$ from the fitted distribution was taken as the best estimate of EF. The best estimates for EFs are given as the $\mu$ of the pdfs in Table 1 . We used published EFs from 46 forest fires (Urbanski et al., 2009b; Friedli et al., 2001; Yokelson et al., 1999; Nance et al., 1993; Radke et al., 1991) and 21 grassland/shrubland fires (Urbanski et al., 2009b; Hardy et al., 1996; Nance et al., 1993; Radke et al., 1991; Coffer et al., 1990) to derive the pdf for EFCO. The pdf for EFPM 2.5 was obtained using EFs from 43 forest fires (Urbanski et al., 2009b; Nance et al., 1993; Radke et al., 1991) and 17 grassland/shrubland fires (Urbanski et al., 2009b; Hardy et al., 1996; Nance et al., 1993; Radke et al., 1991). 


\subsubsection{CO and $\mathrm{PM}_{2.5}$ emission estimates}

Emissions of $\mathrm{CO}$ and $\mathrm{PM}_{2.5}$ were estimated using the bias corrected burned area (Sect. 2.2.3), the best estimate, cover type specific emission factors (Table 1), and the mean of the four FLC predictions (Sect. 2.1.5, Table 1). The WFEI model was applied to the 11 western states of the contiguous U.S. for 2003-2008. The model's base resolution of 500 $\mathrm{m}$ and 1 day was defined by the MODIS burned area product. The burned area is derived from the 24 hour increase in burn scar area (500 m spatial resolution) which is mapped once per day using the combined MODIS data from the daytime overpasses of the Terra and Aqua satellites (Sect. 2.1.1). Emissions of $\mathrm{CO}$ and $\mathrm{PM}_{2.5}$ were estimated at multiple levels of spatio-temporal aggregation (Sect. 2.2.1), with daily sums on a $10 \mathrm{~km}$ grid being the finest scale and annual, domain wide emissions as the most coarse scale.

\subsection{Evaluation of emission model uncertainty}

\subsubsection{Spatial and temporal aggregation}

The emission model has a base resolution of $500 \mathrm{~m}$ and 1 day. To evaluate the dependence of the model's uncertainty to scale, the base resolution ( $500 \mathrm{~m}$ and 1 day) emission inventory was aggregated across multiple spatial grids $(\Delta x=$ $10,25,50,100,200 \mathrm{~km})$ and time steps $(\Delta t=1,5,10,30,365$ day) providing 25 arrays, $g_{\Delta x, \Delta t}(k, t)$. We use $\Delta x$ and $\Delta t$ to refer to the spatial and temporal scales of aggregation, respectively. The following notation will be used to identify a particular spatio-temporal aggregation of the emission model: $g_{25 \mathrm{~km}, 30 \text { day }}(k, t)$. "Elements" will be used to refer the array elements $(k, t)$ of a particular spatio-temporal aggregate. For example, the $25 \mathrm{~km} \times 25 \mathrm{~km}$ grid $(\Delta x=25 \mathrm{~km})$ has 7020 grid cells and our 6 year study has 7230 day time periods ( $\Delta t=30$ day). Thus, the spatio-temporal aggregate $g_{25 \mathrm{~km}, 30 \text { day }}(k, t)$ has 505440 elements; however, not all of the elements are a source of fire emissions. The extent of the study's spatial and temporal domains were the 11 western United States and from 1 January 2003 to 31 December 2008 , respectively. The span of the spatial resolution was chosen to cover both regional $(\leqslant 25 \mathrm{~km})$ and global $(50 \mathrm{~km}$ to $200 \mathrm{~km}$ ) atmospheric chemical transport modeling applications.

\subsubsection{Monte Carlo analysis}

The uncertainty of the emission model was estimated using a Monte Carlo analysis. The emission model is characterized by large uncertainties and non-normal distributions. Monte Carlo analysis is a suitable approach for assessing the uncertainty of such a model (IPCC, 2006) and has been applied in previous BB EI studies (van der Werf et al., 2010; French et al., 2004). In this paper we use $\sigma_{X}$, where $X=A$, FLC, or EF $(i)$, to signify the 1-sigma $(1 \sigma)$ uncertainty of the model variables. The $\sigma_{\mathrm{X}}$ are the standard deviation of the model components used in the Monte Carlo analysis. The probability distribution functions (pdf) and parameters $\sigma_{\mathrm{X}}$ and $\mu_{\mathrm{X}}$ (the mean of $\mathrm{X}$ which is used as the best estimate of $\mathrm{X}$ ) for A, FLC, and EF ( $i$ ) are given in Table 1. The approaches used to determine the pdf and parameters in Table 1 and their application in the Monte Carlo analysis are described in following sections. We use $u_{\mathrm{X}}$, where $\mathrm{X}=\mathrm{A}, \operatorname{FLC}, \mathrm{EF}(i)$, to refer to the $1 \sigma$ fractional uncertainty in estimated value of $\mathrm{X}$, $u_{\mathrm{X}}=\sigma_{\mathrm{X}} / \mu_{\mathrm{X}}$.

\subsubsection{Burned area mapping uncertainty}

\section{MODIS vs. MTBS “ground truth"}

We used burn severity and fire boundary geospatial data from the Monitoring Trends in Burn Severity (MTBS) project (MTBS, 2011a, b) to develop "ground truth" burned area maps to evaluate the uncertainty in our MODIS burned area product. MTBS is an ongoing project designed to consistently map the burn severity and perimeters of large fire events (>404 ha) across the United States (MTBS, 2011c). The project uses LANDSAT TM/ETM images to identify fire perimeters and classify burn severity by 5 categories ( $1=$ unburned to low severity, $2=$ low severity, $3=$ moderate severity, $4=$ high severity, and $5=$ increased greenness). The fire severity classification is based on the differenced normalized burn ratio (dNBR) calculated from pre-fire and postfire LANDSAT images. MTBS analysts develop fire severity classifications from the dNBR for each individual fire event using raw pre-fire and post-fire imagery, plot data, and analyst experience with fire effects in a given ecosystem. We identified the annual "ground truth" burned area using the Regional MTBS Burn Severity Mosaic geospatial data (MTBS, 2011b). We mapped the "true" burned area from the MTBS dataset by classifying all pixels with an MTBS severity class 2,3 , or 4 as burned.

The uncertainty assessment for our improved MODIS burned area mapping algorithm used data from 11 subregions representing the different land cover types of the western United States. The general approach was to aggregate the MODIS and MTBS burned pixels by the cells of a $25 \mathrm{~km} \times 25 \mathrm{~km}$ evaluation grid on an annual basis. The MTBS project mapped only large fires $\left(>4 \mathrm{~km}^{2}\right)$, and while our MODIS burned area mapping algorithm was designed for large wildfire events, it does detect and map fires $<4 \mathrm{~km}^{2}$ (Urbanski et al., 2009a). Therefore it is possible that our MODIS burned area mapping algorithm may accurately map small fire events that are not included in the MTBS dataset and that these MODIS detected burned pixels would improperly contribute to our assessment as false positive error. As a result, we screened our MODIS data for burned pixels that were not associated with MTBS mapped fire events. MODIS active fire detections not within $3 \mathrm{~km}$ of an MTBS fire boundary (MTBS, 2011a) were flagged and the burn pixels confirmed by these active fire detections were excluded 
from the assessment. Even after spatial filtering, the screened MODIS burn pixels may include areas associated with small prescribed fires that were not mapped by MTBS but occurred near MTBS mapped fires. Because the majority of prescribed burning in the western United States is conducted prior to (or after) a region's wildfire season, we identified, annually, the approximate commencement date for wildfire activity within each evaluation zone from the MTBS fire boundary data (MTBS, 2011a). Within each subregion (on an annual basis) we used the earliest reported start date from the MTBS perimeter data to identify the onset of wildfire activity. MODIS burned pixels in a particular evaluation zone which predated the beginning of wildfire activity by more than 1 week were assumed to be prescribed fires and excluded from the burned area assessment. We did not develop a filter for post-season prescribed burns and such burns could be included in our assessment as false positive error. Within each subregion, the filtered MODIS burned area and the MTBS based burned area were aggregated by the $25 \mathrm{~km}$ grid cells on an annual basis. The evaluation used data selected from 2005, 2006, and 2007, but in only a few cases was more than one year of data used in any subregion. The total burned area in the 11 subregions used in the uncertainty analysis was $23012 \mathrm{~km}^{2}$ for MTBS and $22027 \mathrm{~km}^{2}$ for the filtered MODIS data. Prior to filtering, the MODIS burned area was $24084 \mathrm{~km}^{2}$. The MTBS proximity filter and the pre-season prescribed fire filter were only used in the burned area uncertainty evaluation which quantified the uncertainty function (Eq. 3) and corrected the algorithm's mean bias (see below). The burned area used in the emission inventory that is presented and discussed in Sects. 3-5, included all MODIS based burned pixels as mapped with the algorithm as described in Sect. 2.1.1.

We found that the MODIS burned area product was in close agreement with the MTBS burned area (Fig. 1). The coefficient of determination $\left(r^{2}=0.91\right)$ and the Theil-Sen (TS) regression estimator value indicated our MODIS burned area product slightly overestimated burned area by $7 \%$ (see Fig. 1). The TS regression estimator was selected over ordinary least squares regression because the burned area data in this study is non-normal distributed, heteroscedastic (the variance of the error term is not constant), and contains high leverage outliers. The TS estimator is somewhat resistant to outliers and tends to yield accurate confidence intervals when data is heteroscedastic and non-normal in distribution (Wilcox, 1998, 2005). The slope value of the TS estimator did not change when the intercept was forced to zero. The MODIS burned area was adjusted by the TS estimator slope (0.93) to correct for the slight overestimation. The MODIS burned area used throughout the remainder of this paper is the adjusted MODIS burned area.

\section{Uncertainty quantification}

A primary goal of this study was to characterize the uncertainty in a biomass burning emission model, a task that requires uncertainty estimates for each model component. The burned area data has a non-normal distribution and is heteroscedastic. The heteroscedasticity in the dataset is readily apparent; the variation in the MODIS burned area differs depending on the value of the "ground truth", and the scatter (error) increases with increasing burned area (see Fig. 1). The default Breusch-Pagan test for linear forms of heteroscedasticity was used to formally verify the heteroscedastic condition of the dataset.

When data is non-normal in distribution and heteroscedastic, standard approaches for quantifying uncertainty are not reliable (Wilcox, 2005). Therefore, following Urbanski et al. (2009a) and Giglio et al. (2010), we employed an empirical error estimation approach to quantify the uncertainty of our MODIS based burned area measurement. The details of this analysis are provided in Appendix A and only the results are presented in this section. As evident in Fig. 1, and as demonstrated by Urbanski et al. (2009a), and by Giglio et al. (2010) (who used a more sophisticated MODIS burn scar mapping technique) our analysis found that absolute uncertainty increases with increasing burned area. The $1 \sigma$ uncertainty in our MODIS mapped burned area is:

$\sigma_{A}=(\mathrm{b} \times \mathrm{A})^{1 / 2}$

where $\mathrm{A}$ is the MODIS measured burned area in $\mathrm{km}^{2}$ and $\mathrm{b}=5.03 \mathrm{~km}^{2}$. The development of Eq. (3) is described in Appendix A. While the absolute uncertainty $\left(\sigma_{A}\right)$ increases with burned area, the relative uncertainty $\left(u_{\mathrm{A}}=\sigma_{\mathrm{A}} / \mathrm{A}\right)$ decreases. For example, $u_{\mathrm{A}}=0.71$ for a measured burned area of $\mathrm{A}=10 \mathrm{~km}^{2}$ and decreases to 0.22 at $\mathrm{A}=100 \mathrm{~km}^{2}$. Uncertainty is typically expressed as an interval about a measurement result that is expected to encompass a specified probability range of the true value. In this study we defined the burned area uncertainty, $u_{\mathrm{A}}$, as the error cone expected to contain approximately $68 \%$ of the "ground truth" burned area values of which the MODIS burned area is a measurement. This definition of uncertainty provides coverage comparable to that of a standard uncertainty for normally distributed data (i.e. coverage of $\sim 68 \%$ for $1 \sigma$ ). The empirical uncertainty analysis employed in this study (see Appendix A) satisfies our definition of uncertainty. Seventy two percent of the "ground truth" burned area values fall within the uncertainty bounds (Eq. 3) and when a coverage factor of 1.65 is applied (i.e. the 90 percent confidence interval of a normal distribution), $87 \%$ of the "ground truth" values are enveloped by the resulting uncertainty bounds (Fig. A2).

\subsubsection{Fuel load consumption uncertainty}

The combination of fuel loading maps (FLM, FCCS) and consumption models (FOFEM, CONSUME) provided four 


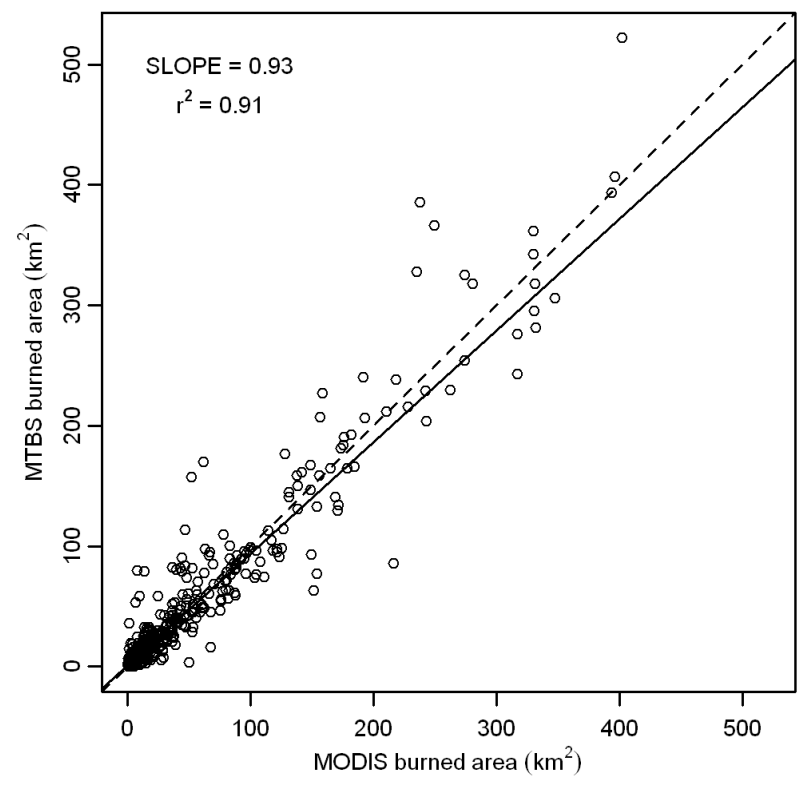

Fig. 1. MODIS mapped burned area plotted against the MTBS burned area for 463 grid cells $(25 \mathrm{~km} \times 25 \mathrm{~km})$. The solid line is the Theil-Sen estimate of the slope, slope $=0.93_{0.90}^{0.96}$; uncertainty is $90 \%$ confidence interval, the coefficient of determination is $r^{2}=$ 0.91 . The dashed line is $1: 1$.

predictions of fuel load consumption (Eq. 2, Sect. 2.1.5) At each element of the $g_{\Delta x, \Delta t}(k, t)$ we aggregated base resolution FLC data (500 $\mathrm{m}$ and 1 day) by summing each of the four $\mathrm{FLC}_{i, j}$ at each grid $(k)$ and time step $(t)$ and then using the mean of the four predictions as the best estimate of FLC ( $\mu_{\text {FLC }}$, Table 1). Sufficient observational data is not available to evaluate the estimates of FL, C or FLC; therefore, a statistical sample of the prediction error could not be used to quantify the uncertainty in the FLC. We made the subjective decision to estimate the uncertainty in the FLC predictions $\left(\sigma_{\mathrm{FLC}}\right.$, Table 1$)$ as $50 \%$ of the range. Our uncertainty analysis does not account for mapping error, i.e. incorrect assignment of fuel code in the LANDFIRE geospatial data. Mapping error could not be considered due to the absence of appropriate independent data.

\subsubsection{Emission factor uncertainty}

Published studies of over 50 fires in the United States and southwestern Canada (Sect. 2.1.5) were used to develop the forest and non-forest cover type pdf for EFCO and EFPM 2.5 in Table 1. The statistical variability of each EF (CO or $\mathrm{PM}_{2.5}$, forest or non-forest) was determined by fitting lognormal and normal distributions to the source data. With the exception of EFCO for forest cover type, the EF were best described with a log-normal distribution. For each EF, the distribution model and fitted parameters $(\mu$ and $\sigma)$ were used in the Monte Carlo simulations (Sect. 2.2.2) to estimate the uncertainty. $\mu$ was taken as the best estimate of EF. The pdf and parameters are given in Table 1.

\subsubsection{Emission inventory uncertainty}

The Monte Carlo analysis provided estimates of the model uncertainty for ECO and $\mathrm{EPM}_{2.5}$ at multiple scales by conducting 10000 simulations at each of the 25 spatio-temporal aggregates, $g_{\Delta x, \Delta t}(k, t)$. In each simulation round, possible $\mathrm{CO}$ and $\mathrm{PM}_{2.5}$ emission values for each element were calculated using Eq. (1) where the values A, $\operatorname{FLC}, \operatorname{EF}(i)$ were obtained by random sampling from each component's pdf (Table 1). We note that the burned area pdf was based on an analysis at a spatial scale of $25 \mathrm{~km}$ but is used across all scales $(\Delta x=10 \mathrm{~km}$ to $\Delta x=200 \mathrm{~km})$ in the Monte Carlo analysis. Both forest and non-forest EF values were drawn and the cover type weighted average of the two was used as the EF $(i)$ at each element. The simulations provided 10000 ECO and EPM25 estimates for each element of each $g_{\Delta x, \Delta t}(k, t)$, which served as the emission model pdf. The best estimate of ECO and $\mathrm{EPM}_{2.5}$ at each element ( $\mu_{\mathrm{ECO}}$ and $\mu_{\mathrm{EPM}_{25}}$ ) was calculated with Eq. 1 using the mean values in Table 1The simulation results for ECO and $\mathrm{EPM}_{2.5}$ were each sorted by increasing value and the $1 \sigma$ uncertainty bounds were taken as the 16th and 84th percentiles (elements $\mathrm{B}_{l}=1600$ and $\mathrm{B}_{u}=8400$ of the sorted simulation, respectively). Likewise, $90 \%$ confidence intervals were taken as the 5th and 95th percentiles, $\mathrm{B}_{l}=500, \mathrm{~B}_{u}=9500$. The uncertainty bounds produced in this analysis are not symmetric due to truncation of negative values and the log-normal nature of $\mathrm{EFPM}_{2.5}$ and the EFCO for non-forest cover types (Table 1). When the uncertainty in the burned area was larger than the absolute burned area the lower uncertainty bound was truncated to 0 . This truncation contributes to skewed uncertainty bounds for the emission estimates with $\sigma_{\mathrm{EX}}$ (upper) $>\sigma_{\mathrm{EX}}$ (lower). The truncation effects associated with the burned area were most prevalent at small aggregation scales. The FLC pdf occasionally produced an uncertainty that was larger than $\mu_{\mathrm{FLC}}$ resulting in a negative lower uncertainty bound which was truncated to 0 . Throughout the paper we use the larger, upper uncertainty bounds (84th or 95th percentiles) when referring to absolute or relative uncertainties. The nomenclature $\sigma_{\mathrm{EX}}$ and $u_{\mathrm{EX}}$ refers to the upper bound, $1 \sigma$ absolute uncertainty and fractional uncertainty in $\mathrm{EX}\left(u_{\mathrm{EX}}=\sigma_{\mathrm{EX}} / \mathrm{EX}\right)$, respectively. For each element with WF emissions at a given $g_{\Delta x, \Delta t}(k, t)$ our analysis provides a best estimate of EX and estimates of uncertainty $\sigma_{\mathrm{EX}}$ and $u_{\mathrm{EX}}$. Note that $\mathrm{A}\left(\mu_{\mathrm{A}}\right.$ in Table 1$)$, is simply the MODIS burned area measurement for each element and that EF $(i)$ is the cover type weighted average of the appropriate $\mu$ from Table 1. 

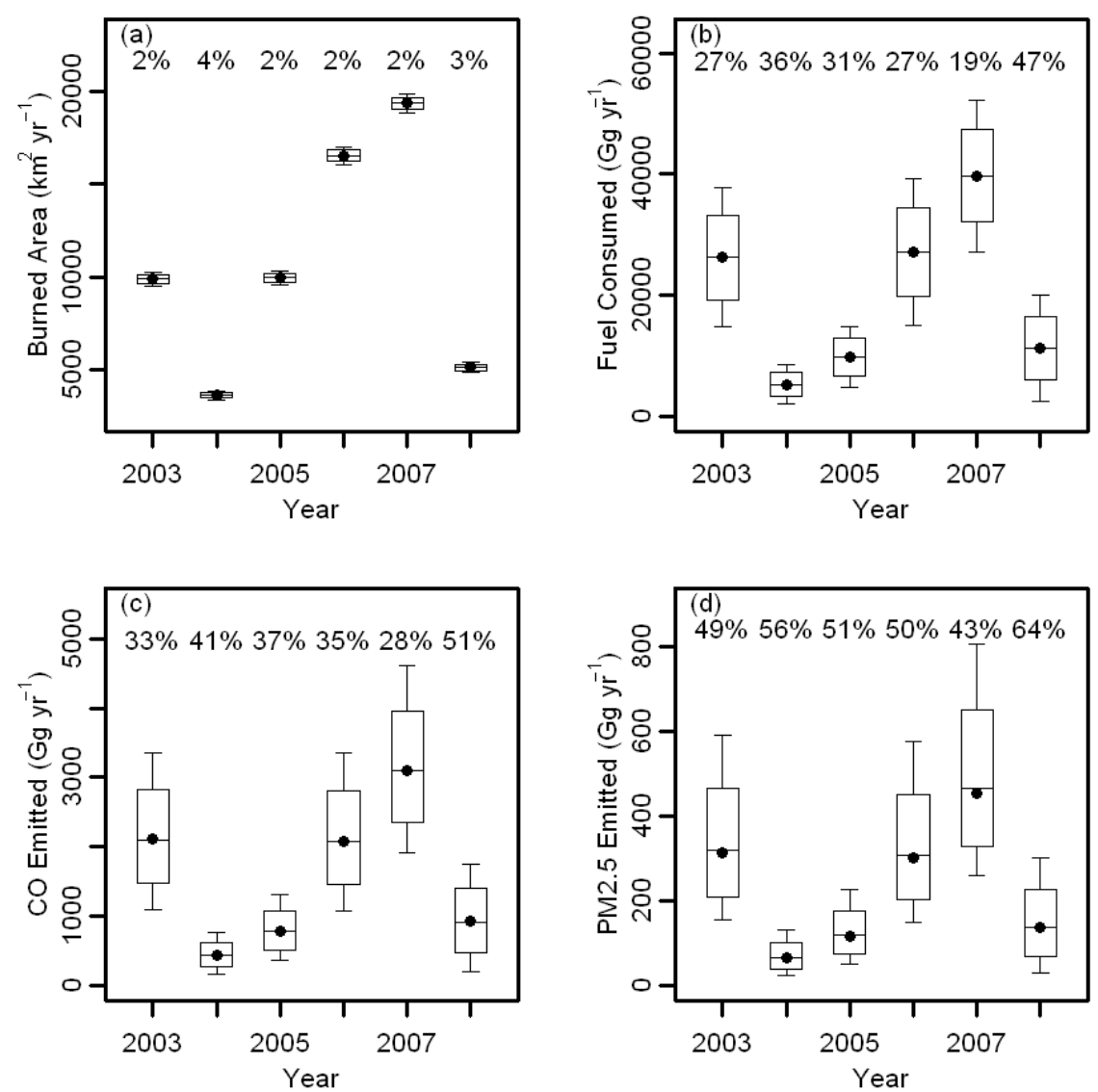

Fig. 2. Estimates of western United States annual (a) burned area, (b) fuel consumption, (c) CO emitted, and (d) $\mathrm{PM}_{2.5}$ emitted. Solid points are the best estimate. The solid horizontal lines, boxes, and whiskers denote the median, $1 \sigma$ uncertainty and 90 percent confidence interval, respectively, from the Monte Carlo analysis. Numbers give $1 \sigma$ as percentage of the best estimate.

\subsubsection{Variability and sensitivity of emission model uncertainty}

In order to evaluate the uncertainty in our emission estimates across multiple scales we used a figure of merit, the half mass uncertainty, $\tilde{u}_{\mathrm{EX}}$ (where $\mathrm{X}=\mathrm{CO}$ or $\mathrm{PM}_{2.5}$ ), defined such that for a given aggregation level $50 \%$ of total emissions occurred from elements with $u_{\mathrm{EX}}<\tilde{u}_{\mathrm{EX}}$. The figure of merit was calculated as follows: for each $g_{\Delta x, \Delta t}(k, t)$, paired $u_{\mathrm{EX}}$ and $\mathrm{EX}$ were sorted in order of ascending $u_{\mathrm{EX}}$ and the figure of merit was taken as the value of $u_{\mathrm{EX}}$ where the cumulative sum of EX exceeded $50 \%$ of total EX. A graphical demonstration of $\tilde{u}_{\mathrm{EX}}$ is provided in Fig. S1. Thus, at a given $g_{\Delta x, \Delta t}(k, t)$, $50 \%$ of total ECO $\left(\mathrm{EPM}_{2.5}\right)$ is estimated with an uncertainty less than $\tilde{u}_{\mathrm{ECO}}\left(\tilde{u}_{\mathrm{EPM}_{2.5}}\right)$.

We estimated the sensitivity of the uncertainty in our emission estimates to uncertainties in the model components using Eq. (4):

$\lambda_{\mathrm{EX}, i}=\frac{\partial \tilde{u}_{\mathrm{EX}}}{\partial \alpha_{i}}$ where $\sigma_{i}$ is the uncertainty in one of the model components $(i=\mathrm{A}, \mathrm{FLC}, \mathrm{EF})$. One model component at a time, the $1 \sigma$ uncertainties from Table 1 were varied by a factor of $\alpha=0.30$ to 1.70 with an increment of 0.1 . For each increment in $\alpha$, the Monte Carlo analysis was repeated and the figure of merit, $\tilde{u}_{\mathrm{EX}}$, was determined. Then the $\tilde{u}_{\mathrm{EX}}$ for all $\alpha$ increments was regressed against $\alpha$ and the slope of this regression provided the value of $\lambda_{E X, i}$ (Fig. S2). These steps were repeated across each of the 25 spatio-temporal aggregates for all $\sigma_{i}$.

\section{Results}

\subsection{Emissions, burned area, and fuel consumption}

Estimated annual burned area, fuel consumption (FC; $\mathrm{FC}=\mathrm{A} \times \mathrm{FLC}$ ), and emitted $\mathrm{CO}$ and $\mathrm{PM}_{2.5}$ for the western United States are shown in Fig. 2. The annual values and uncertainties were derived by annual aggregation of the base resolution $(500 \mathrm{~m}$ and 1 day) model components and emission estimates. The annual sums of A, FC, ECO, and 

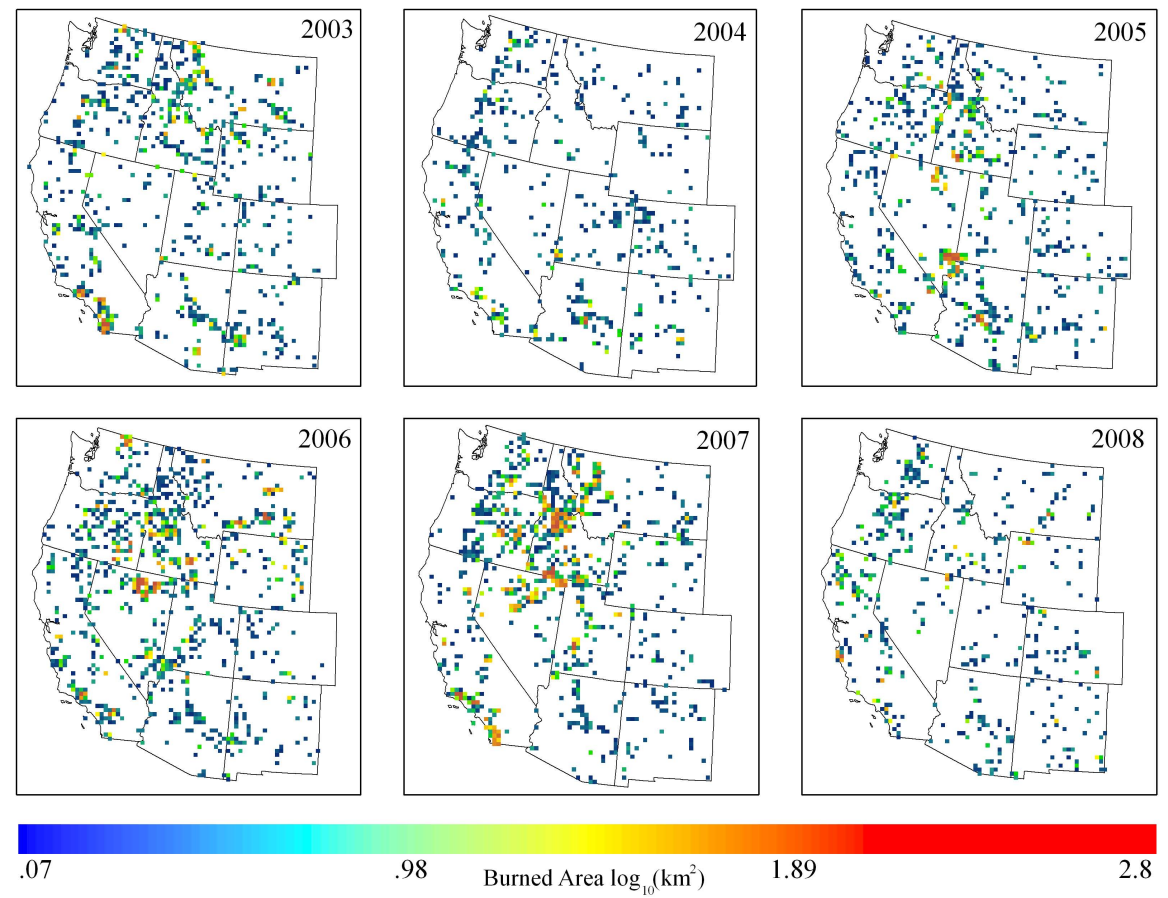

Fig. 3. Annual burned area aggregated as square $\mathrm{km}$ burned per $25 \mathrm{~km} \times 25 \mathrm{~km}$ grid cell displayed in log scale.
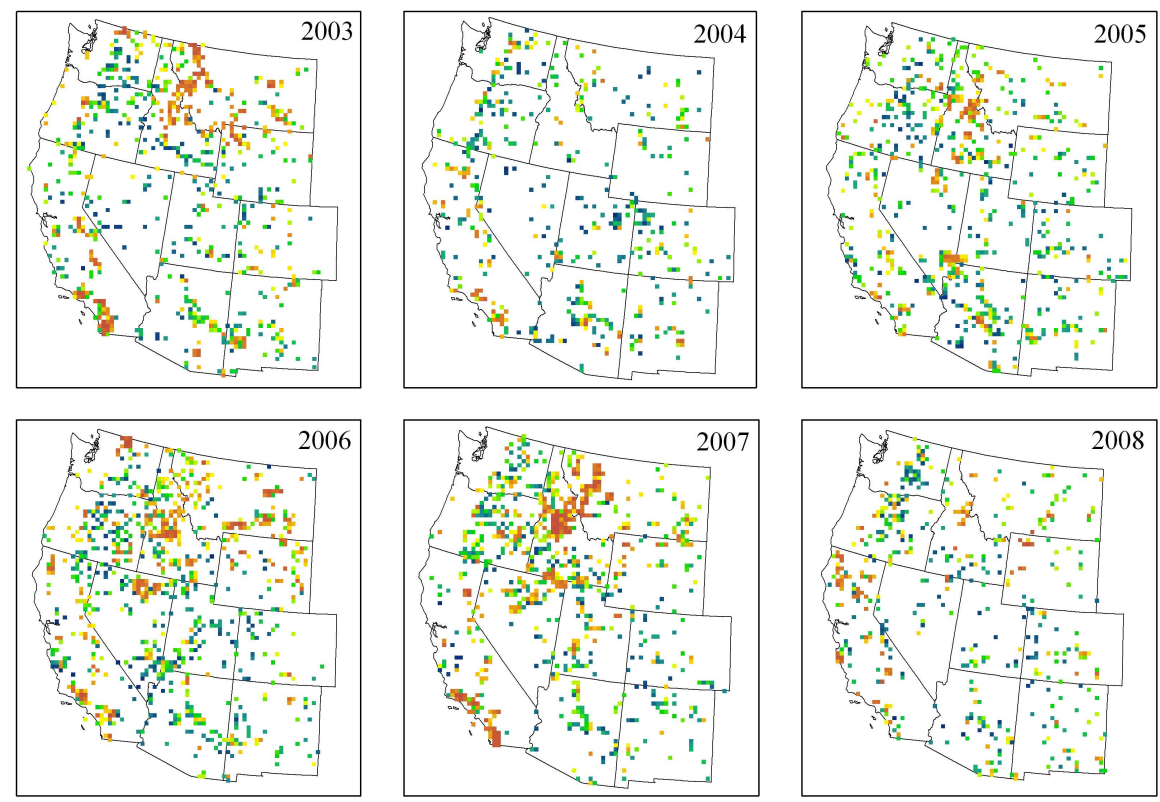

4.9

$6.3 \quad$ Fuel Consumed $\log _{10}(\mathrm{~kg})$

7.8

9.2

Fig. 4. Annual fuel consumed aggregated as kg dry vegetation burned per $25 \mathrm{~km} \times 25 \mathrm{~km}$ grid cell displayed in log scale.

$\mathrm{EPM}_{2.5}$ for each of the 11 states are provided in Tables 2 through 5. Maps of the annual burned area, fuel consumption, and emissions, aggregated to the $\Delta x=25 \mathrm{~km}$ grid (i.e. $\left.g_{25 \mathrm{~km}, \Delta 365 d}(k, t)\right)$ are given in Figs. 3 through 6 . There was significant inter-annual variability in the burned area, fuel consumption, and emissions. The annual burned area ranged 

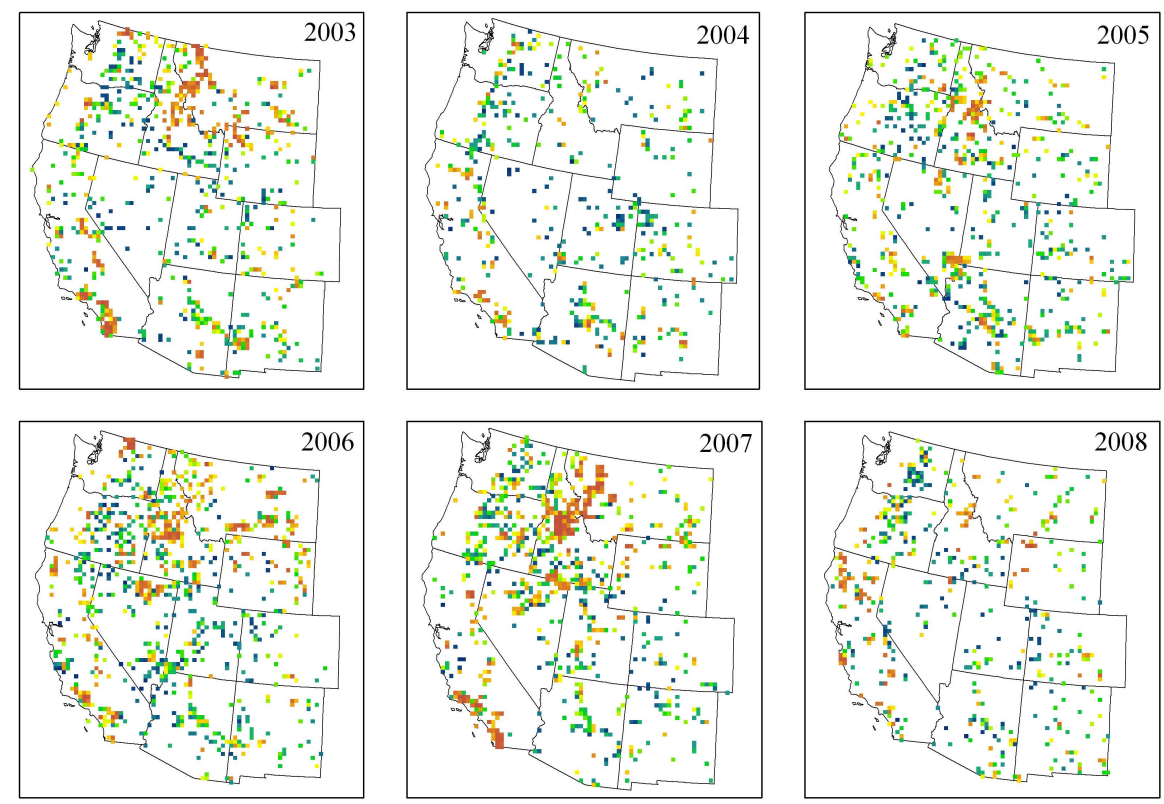

3.9

5.3

CO Emitted $\log _{10}(\mathrm{~kg})$

6.7

Fig. 5. Annual CO emissions aggregated as $\mathrm{kg} C \mathrm{CO}$ per $25 \mathrm{~km} \times 25 \mathrm{~km}$ grid cell displayed in log scale.
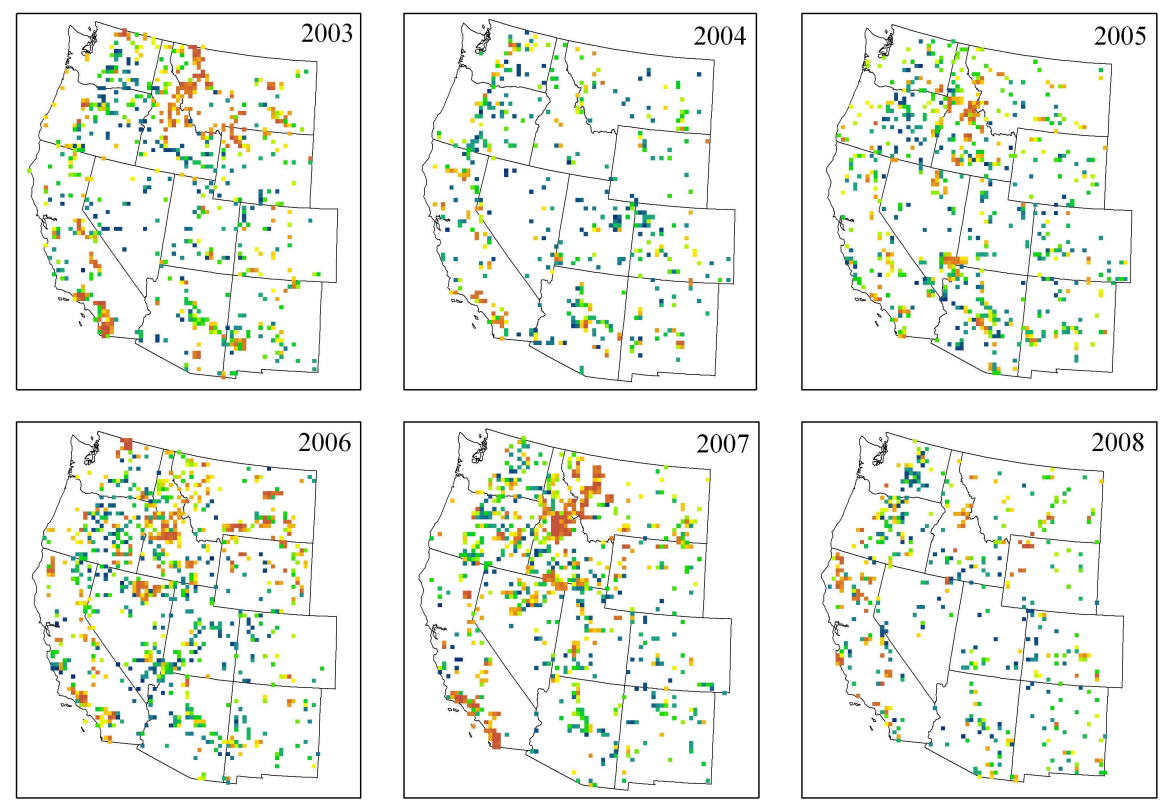

3.0

4.4 PM 2.5 Emitted $\log _{10}(\mathrm{~kg})$

5.8

Fig. 6. Annual $\mathrm{PM}_{2.5}$ emissions aggregated as $\mathrm{kg} \mathrm{PM}_{2.5}$ per $25 \mathrm{~km} \times 25 \mathrm{~km}$ grid cell displayed in log scale.

from 3622 to $19352 \mathrm{~km}^{2}$. Fuel consumption was 5292 to $39710 \mathrm{Gg}$ dry vegetation $\mathrm{yr}^{-1}$. Annual total ECO was 436 to $3107 \mathrm{Gg} \mathrm{yr}^{-1}$ and annual total emissions of $\mathrm{PM}_{2.5}$ were 65 to $454 \mathrm{Gg} \mathrm{yr}^{-1}$. Annual total burned area, fuel consumption, $\mathrm{ECO}$, and $\mathrm{EPM}_{2.5}$ were all largest in 2007, and smallest in 2004; with 2007 emissions being 7 times those in 2004 . 
Table 2. Annual sums of state level burned area estimates $\left(\mathrm{km}^{2} \mathrm{yr}^{-1}\right)$ over 2003-2008.

\begin{tabular}{|c|c|c|c|c|c|c|c|c|}
\hline State & 2003 & 2004 & 2005 & 2006 & 2007 & 2008 & Total & Contribution $^{\mathrm{b}}$ \\
\hline Arizona (AZ) & 727 & 841 & 1788 & 486 & 356 & 268 & 4466 & $6.9 \%$ \\
\hline California (CA) & 2958 & 884 & 815 & 1940 & 3463 & 1742 & 11802 & $18.3 \%$ \\
\hline Colorado (CO) & 222 & 233 & 195 & 187 & 139 & 336 & 1312 & $2.0 \%$ \\
\hline Idaho (ID) & 994 & 109 & 1745 & 2462 & 6128 & 346 & 11784 & $18.3 \%$ \\
\hline Montana (MT) & 1955 & 134 & 330 & 2669 & 2026 & 398 & 7512 & $11.7 \%$ \\
\hline New Mexico (NM) & 596 & 309 & 377 & 378 & 170 & 315 & 2145 & $3.3 \%$ \\
\hline Nevada (NV) & 192 & 169 & 2840 & 3979 & 2687 & 332 & 10199 & $15.8 \%$ \\
\hline Oregon (OR) & 641 & 267 & 662 & 1949 & 2037 & 657 & 6213 & $9.6 \%$ \\
\hline Utah (UT) & 415 & 344 & 603 & 642 & 1331 & 88 & 3423 & $5.3 \%$ \\
\hline Washington (WA) & 742 & 246 & 449 & 1068 & 739 & 299 & 3543 & $5.5 \%$ \\
\hline Wyoming (WY) & 438 & 85 & 141 & 767 & 276 & 346 & 2053 & $3.2 \%$ \\
\hline Total $^{\mathrm{a}}$ & $9879 \pm 2 \%$ & $3622 \pm 4 \%$ & $9945 \pm 2 \%$ & $16526 \pm 2 \%$ & $19352 \pm 2 \%$ & $5128 \pm 3 \%$ & $64452 \pm 2 \%$ & $100.0 \%$ \\
\hline
\end{tabular}

${ }^{\mathrm{a}}$ Uncertainties are $1 \sigma$ (see Sect. 2.2.3). ${ }^{\mathrm{b}}$ Contribution is the percent contribution of estimated burned area in each state to the 6 year total.

Burned area alone did not drive emissions. The significance of the ecosystems burned to fuel consumption and total emissions is easily seen by examining the years 2003, 2005, and 2006. In 2003 and 2005, the burned area was comparable, but fuel consumption, and thus emissions, were larger by a factor of $\sim 2.7$ in 2003. The large difference in burned area between $2003\left(9879 \mathrm{~km}^{2}\right)$ and $2006\left(16526 \mathrm{~km}^{2}\right)$, ECO and $\mathrm{EPM}_{2.5}$ differed by only a few percent. These differences are not simply a function of the forested to non-forested burned area ratio, e.g. the fraction of forested burned area in 2003 and 2005 were roughly the same. And while in 2006 the fraction of burned area that was forest (49\%) was smallest of the six years, emission per area burned in 2006 exceeded that in 2004 and 2005 when $77 \%$ and $68 \%$ of burned area was forest, respectively.

State level, annual burned area, fuel consumption, total ECO and $\mathrm{EPM}_{2.5}$ are included in Tables 2-5. Spatially, fire emissions were concentrated in three regions: Idaho and western Montana; southern California; and central Oregon and Washington (Figs. 5 and 6). Nearly half of the total estimated burned area over 2003-2008 occurred in three states: California (18.3\%), Idaho (18.3\%), and Montana $(11.7 \%)$. These three states accounted for two-thirds of estimated CO and $\mathrm{PM}_{2.5}$ emissions. Fire activity in Nevada comprised a large fraction of the total burned area $(15.8 \%)$, but owing to the sparse vegetation and light fuel loads of Nevada's dominant ecosystems, ECO and $\mathrm{EPM}_{2.5}$ in this state were only a few percent of the domain wide emissions.

During our 6-year study period, fire activity exhibited significant intra-annual variability. Burning was largely limited to June-October. More than $90 \%$ of estimated burned area, fuel consumption, and emissions occurred during these months. This temporal pattern is consistent with that of wildfire burned area reported in administrative records covering 2000-2010 (National Interagency Coordination Center, 2011). The spatial distribution of monthly ECO during the fire season, summed over 2003-2008, is displayed in Fig. 7. Monthly burned area and ECO as percentages of the 2003 2008 totals are also given in Fig. 7 (lower right panel). The maximum burned area occurred in July; however, emissions were a maximum in August due to greater fuel consumed as a result of high fuel loadings and similar or lower fuel moistures. The seasonal fire activity originated in the southwest (Arizona, New Mexico, southern Nevada) in June. During July, fire activity expanded northward along the Rocky Mountains and through the Great Basin with the epicenter of activity migrating into northern Nevada and southern Idaho. Fire occurred throughout the interior west and Pacific Northwest over July. By August, fire activity had largely moved into the northern Rocky Mountains and Pacific Northwest. Fire activity decreased in September and, outside of California, was minimal in October. In California, significant fire activity occurred in each month of the June-October period at some point over 2003-2008. October fires accounted for the largest monthly portion of burned area in California (36\%), followed by fires in July (19\%), September (13\%), August (12\%), and June (9\%).

While fire activity was wide spread over the course of the fire season, emissions were highly concentrated. Cumulative distribution functions of estimated $\mathrm{CO}$ emissions versus the fraction of elements with fire activity are shown in Fig. 8. As described in Sect. 2.2.1, "elements" refers to the array elements $(k, t)$ of a particular spatio-temporal aggregate. From Fig. 8 it is readily apparent that a small fraction of elements were responsible for the majority of total emissions. At $g_{25 \mathrm{~km}, 30 d}(k, t) 50 \% / 90 \%$ of total ECO originated from $2 \% / 18 \%$ of elements. The pattern is similar, though not as extreme, at $g_{10 \mathrm{~km}, 1 d}(k, t), 50 \% / 90 \%$ of total ECO arose from $5 \% / 35 \%$ of the elements. This result is consistent with previous findings that very large wildfires (burned area $>100 \mathrm{~km}^{2}$ ) accounted for a substantial portion of burned area in the western United States (Urbanski et. al, 2009a). 

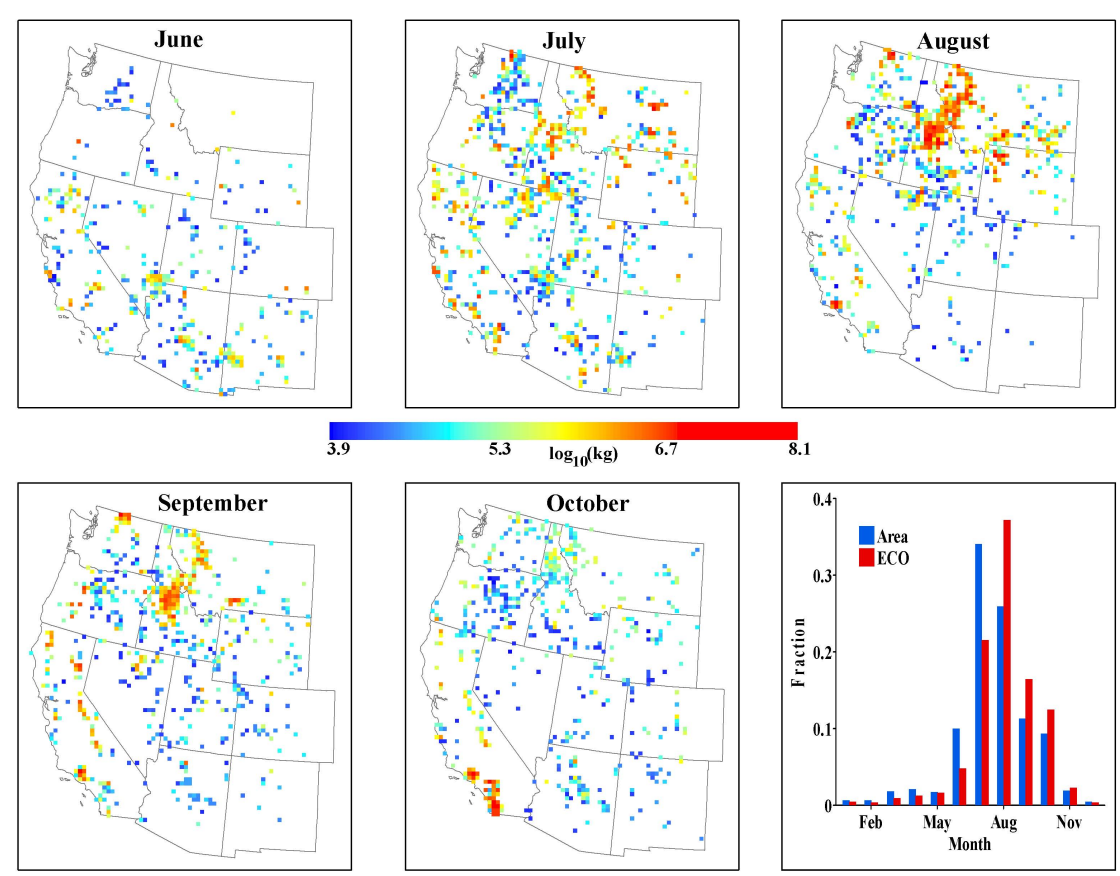

Fig. 7. $25 \mathrm{~km}$ grid cell maps of estimated monthly ECO ( $\mathrm{kg} \mathrm{CO}$ ) summed over 2003 to 2008 and, in the lower right panel, plot of burned area and ECO fractions by month over 2003 to 2008. Maps are log scale.

\subsection{Uncertainty}

\subsubsection{Annual domain wide}

Uncertainty in the estimated annual burned area was $\leq 5 \%$ (Fig. 2a). Due to the large burned area for annual, domain wide aggregation, the lower bound uncertainties were never negative and were not truncated. In this absence of truncation effects, the uncertainty bounds are symmetric. The uncertainties in total, domain wide ECO, which were slightly skewed towards the upper bounds, ranged from $28 \%$ to $51 \%$ (Fig. 2c). The asymmetry in the $u_{\mathrm{ECO}}$ reflects the tail of the log-normal distribution for EFCO in non-forest fuels (Sect. 2.2.3). The uncertainty in estimated $\mathrm{EPM}_{2.5}$ is markedly larger and more skewed than that for ECO. The upper bound fractional uncertainties in $\mathrm{EPM}_{2.5}$ span $43 \%$ $64 \%$ and are 12-15 percentage points higher than those for ECO (Fig. 2d). This difference is due to the larger uncertainty in $\mathrm{EFPM}_{2.5}$ compared with EFCO (Table 1). Fractional uncertainties in the estimated fuel consumption were symmetric and ranged from $19 \%$ to $47 \%$ (Fig. 2b). Because the burned area uncertainty is small for annual, domain wide aggregation, the uncertainty in fuel consumption results primarily from $u_{\text {FLC. }}$. In the absence of independent data for evaluation, we have assumed that the mean and half-range of FLC predicted with the fuel load - consumption model combinations provided a reasonable estimate of true FLC and $u_{\mathrm{FLC}}$, respectively. Given that the true FLC could be quite different from that used here, it is worthwhile to examine the variability of the FLC combinations that provided our best estimate. Figure 9a shows the annual, domain wide FLC predicted by each fuel load - consumption model combination. For both fuel consumption models, the FCCS predicted FLC was always greatest and exceeded the FLM predictions by $37 \%$ to $189 \%$. The choice of fuel consumption model (FOFEM or CONSUME) had minimal impact (1 to $7 \%$ ) for the FCCS and resulted in only a modest 5 to $10 \%$ difference for the FLM in all years except 2008.

The systemic difference between FCCS and FLM was much greater when forest cover types, which comprised $49 \%$ to $77 \%$ of burned area annually, were examined separately. The range of FLC predictions for all forested area burned was $85 \%$ to $134 \%$ of the mean. The FCCS based FLC was a factor of 2.1 to 4.6 times the FLM based predictions, with the difference being greatest for the CONSUME based calculations. The FLM with the lowest fuel loading (FLM $011,0.2 \mathrm{~kg} \mathrm{~m}^{-2}$ ) accounted for $58 \%$ of the forested burned area and its predominance was a substantial factor behind the large difference in FLC predicted by the FCCS and FLM. For a given fuel loading model, the FOFEM predictions always exceeded those of CONSUME. The difference associated with the fuel consumption model was 19 to $40 \%$ for the FLM and $\leq 12 \%$ for the FCCS. The FLC disparity for the FLM resulted from differences in duff consumption. The average duff consumption predicted by FOFEM was $74 \%$ compared to $43 \%$ predicted by CONSUME. The smaller FLC disparity 


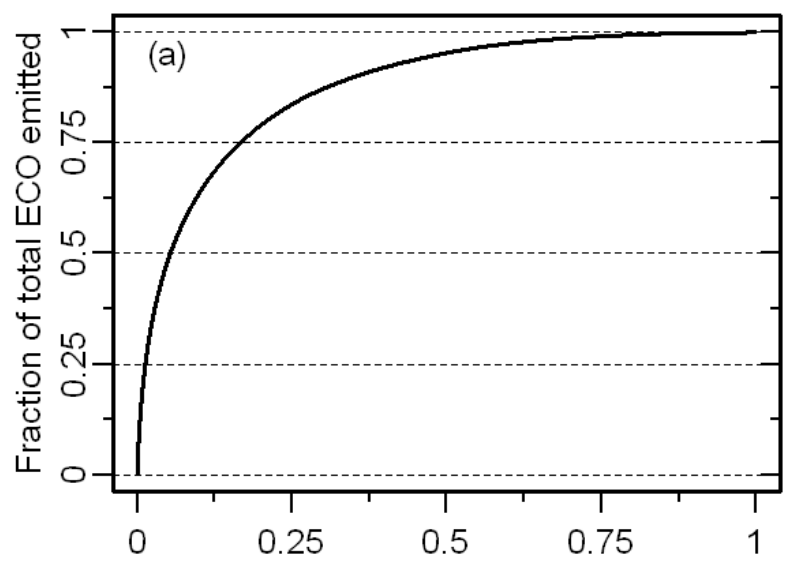

Fraction of elements with fire

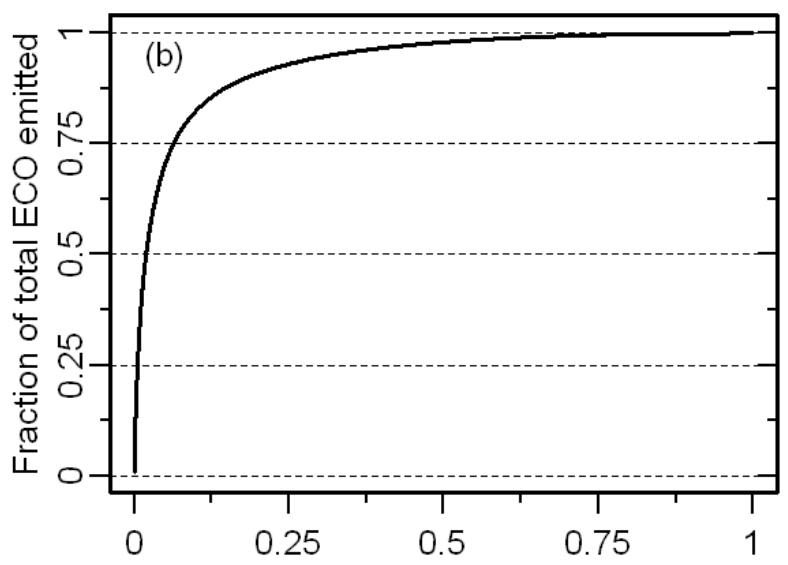

Fraction of elements with fire

Fig. 8. Cumulative Distribution Function of $\mathrm{CO}$ emitted versus fraction of elements with fire. Panel (a) is for data aggregated to $\Delta x=10 \mathrm{~km}$ and $\Delta t=1$ day. Panel (b) is for data aggregated to $\Delta x=25 \mathrm{~km}$ and $\Delta t=30$ day.

simulated using the FCCS was a consequence of the FCCS fuel load distribution. In aggregate the FCCS fuel loads for the forested areas burned in our study had a larger fraction of dead wood (48\%) compared to duff $(41 \%)$, which was opposite of the FLM (33\% dead wood, $51 \%$ duff), and partially offset the duff consumption differences between FOFEM and CONSUME.

In the case of non-forest cover types, there was no systematic difference between the fuel loading models, while the bias of the fuel consumption models was reversed from that observed for forests with CONSUME $>$ FOFEM. The range of FLC predictions was $23 \%$ to $61 \%$ of the mean. The FLC difference due to the fuel consumption models was $18 \%$ to $21 \%$ for the FLM and $4 \%$ to $14 \%$ for the FCCS. In 2003, 2004, and 2007 the FLC based on the FLM exceeded the FCCS based predictions by $30-60 \%$. The large difference
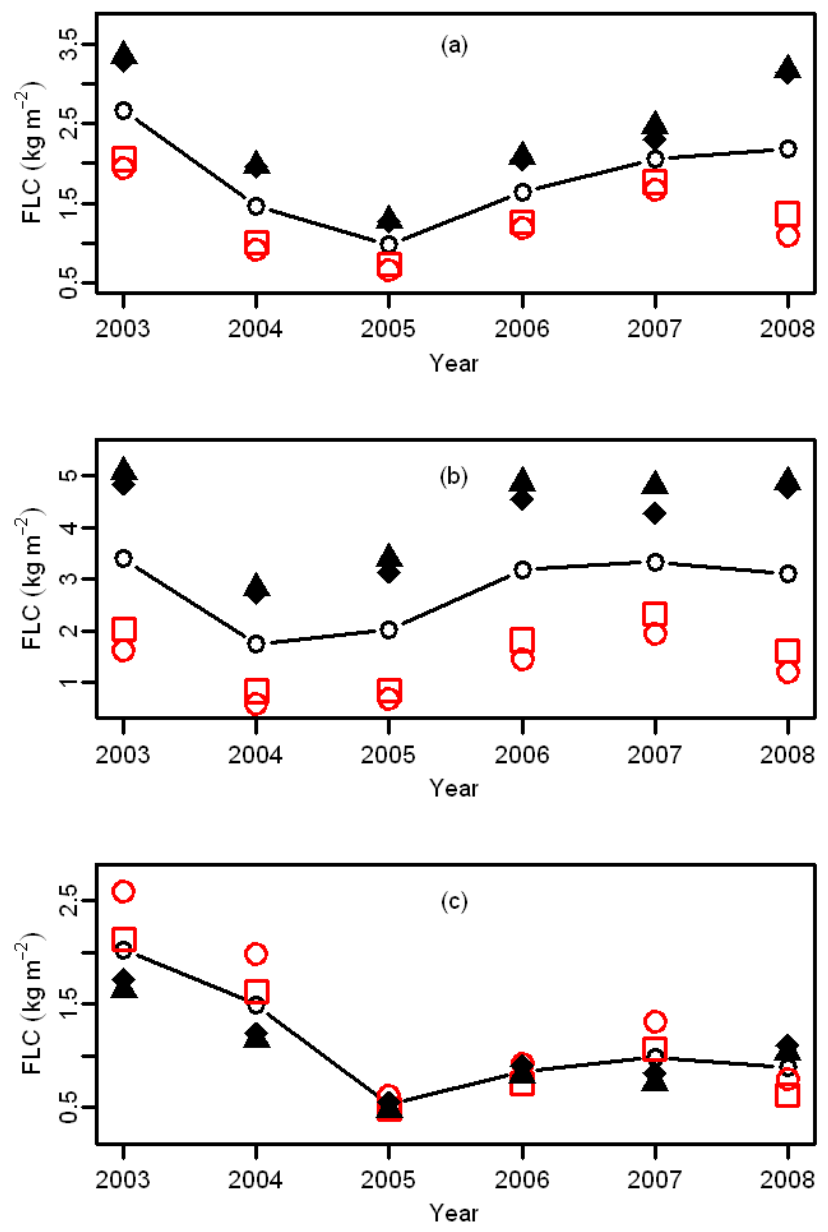

Fig. 9. Estimated annual fuel load consumed (FLC) for different combinations of mapped fuel loads and fuel consumption models, plotted with the following symbols: filled back symbols are FCCS, empty red symbols are FLM, filled black triangles = FCCS and FOFEM, filled black diamonds = FCCS and CONSUME, open red squares $=$ FLM and FOFEM, open red circles $=$ FLM and CON SUME. The average of the four combinations is plotted with the solid line and open black circles. Panel (a) is all cover types, panel (b) is forest cover types, and panel (c) is non-forest cover types. FLC is plotted in units of $\mathrm{kg} \mathrm{m}^{-2}$ for clarity.

between fuel loading models in 2003, 2004, and 2007 resulted largely from the burning of scrub-oak chaparral vegetation in southern California. The supplemental FLM assigned to this vegetation type had a fuel load (FLM $=3003$, see Appendix B) twice that of the corresponding FCCS fuel model $($ FCCS $=2044)$. The persistent FLC differential between fuel consumption models (CONSUME $>$ FOFEM) resulted from differences in the shrub consumption algorithms of the models. The algorithm difference was amplified for the supplemental FLM because the chaparral vegetation types for this model had a larger fraction of their fuel loading in the shrub fuel compared to the FCCS models which tended to have a larger surface fuel component. 

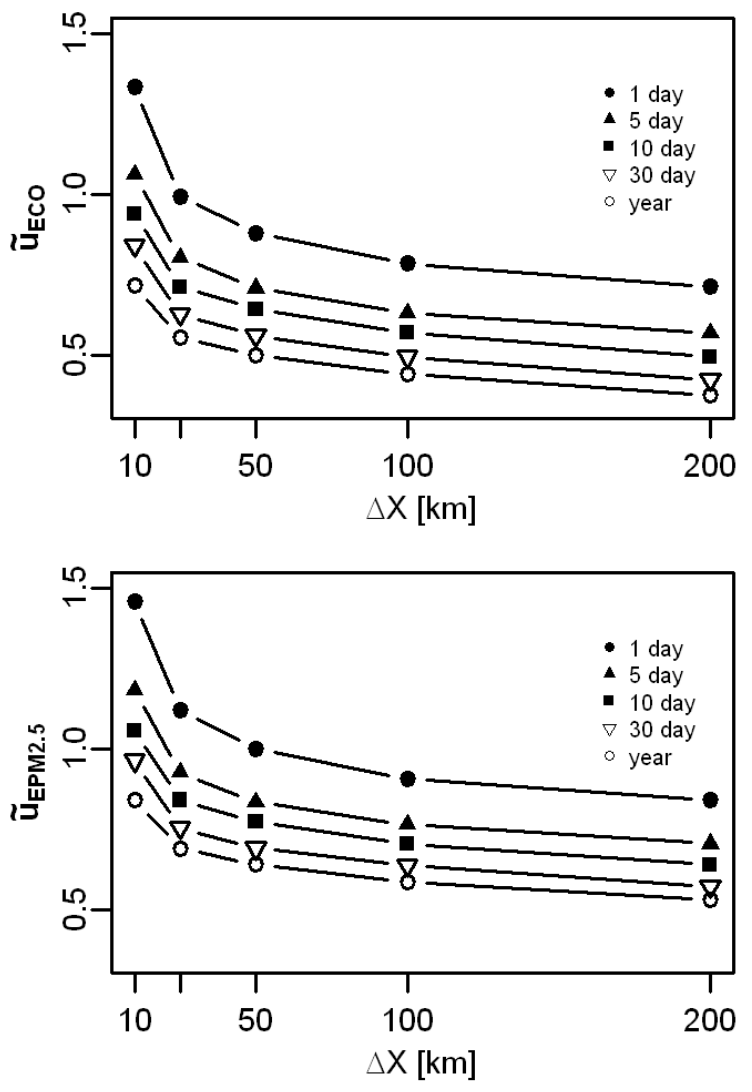

Fig. 10. Plots of $\tilde{u}_{\mathrm{ECO}}$ (top panel) and $\tilde{u}_{\mathrm{EPM}_{2.5}}$ (bottom panel) versus $\Delta x$ for temporal aggregation of $\Delta t=1$ day, 5 day, 10 day, 30 day and 1 year.

\subsubsection{Variation of uncertainty with scale}

Biomass burning emission estimates are commonly employed for a wide-range of tasks and emission uncertainties at the state level on an annual basis are not particularly useful for assessing the appropriateness of an emission inventory for many applications. We have therefore estimated the uncertainties in our emission model across the range of spatial and temporal scales relevant to regional and global atmospheric chemical transport model applications. As discussed in Sect. 3.2.1, the emission estimates have skewed uncertainty bounds, with the upper bound $>$ lower bound. The following analysis uses the larger, upper uncertainty bound.

The variation in $\tilde{u}_{\mathrm{ECO}}$ and $\tilde{u}_{\mathrm{EPM}_{2.5}}$ with scale is displayed in Fig. 10. The uncertainty varies with spatial and temporal aggregation $(\Delta x, \Delta t)$ due the dependence of the burned area fractional uncertainty $\left(u_{\mathrm{A}}\right)$ on fire size. In general, the true burned area in an individual cell increases with $\Delta x$, decreasing the fractional uncertainty in the burned area estimate, and thus $\tilde{u}_{\text {EX }}$ decreases with increasing $\Delta x$. Similarly, at fixed $\Delta x$, the true burned area tends to increase over time, and thus $u_{\mathrm{A}}$, and hence $\tilde{u}_{\mathrm{EX}}$ decreases with increasing $\Delta t$.

\subsubsection{Sensitivity of uncertainty to model components}

The uncertainties in our emission estimates were quite large, particularly at the finer scales. In an effort to identify the most effective approach for reducing uncertainty in ECO and $\mathrm{EPM}_{2.5}$ we conducted a simple sensitivity analysis. The exercise evaluated sensitivity of $\tilde{u}_{\mathrm{ECO}}$ and $\tilde{u}_{\mathrm{EPM}_{2.5}}$ to the model components by separately varying the $1 \sigma$ uncertainty of each component by a factor of 0.3 to 1.7 and repeating the Monte Carlo analysis across scales $\Delta x, \Delta t$ (Sect. 2.2.7). Results of the analysis, presented using the sensitivity factor $\lambda_{\mathrm{EX}, i}$, are displayed versus $\Delta x$ in Fig. 11 for $\Delta t=1$ day and $\Delta t=30$ day. At the scale of global modeling applications ( $\Delta x=50-200 \mathrm{~km}, \Delta t=1$ week-1 month) the sensitivity of $\tilde{u}_{\mathrm{ECO}}$ and $\tilde{u}_{\mathrm{EPM}_{2.5}}$ to the absolute uncertainty $\left(\sigma_{\mathrm{X}}\right)$ in FLC and $\mathrm{A}$ is similar (Figs. 11a and c) with both being more sensitive to $u_{\text {FLC }}$ than $u_{\mathrm{A}}$. However, due to the significant uncertainty in $\mathrm{EFPM}_{2.5}, \tilde{u}_{\mathrm{EPM}_{2.5}}$ is most sensitive to this model component by a considerable margin. In contrast, the EFCO is well characterized and the uncertainty in ECO is relatively insensitive to $u_{\mathrm{EFCO}}$.

Uncertainty in emissions at the scale of regional modeling applications $(\Delta x \leq 25 \mathrm{~km}, \Delta t \leq 1$ day) are most sensitive to $u_{\mathrm{A}}$ for both $\mathrm{CO}$ and $\mathrm{PM}_{2.5}$ (Figs. $11 \mathrm{~b}$ and d). The fractional uncertainty in A increases rapidly with decreasing burned area (Sect. 2.2.3). At aggregation levels relevant for regional modeling the absolute burned area in the elements tends to be relatively small and $u_{\mathrm{A}}$ dominates the uncertainty in emissions.

\section{Discussion}

\subsection{Source contribution and variability}

Forested land covered about $61 \%$ of the total burned area over 2003 to 2008, with minimum and maximum contributions of $49 \%$ in 2006 and $77 \%$ in 2004, respectively. Emissions from forest fires dominated overall WF emissions, accounting for $85 \%$ of emitted $\mathrm{CO}$ and $87 \%$ of emitted $\mathrm{PM}_{2.5}$. Seasonally, burned area peaked in July, while fuel consumption and emissions peaked in August. From 2003 to 2008, $34 \%$ of the total area burned occurred in July and $37 \%$ of total $\mathrm{CO}$ was emitted in August (see Fig. 7). October was the only month where emissions from non-forest cover types exceeded emissions from forests. This resulted from large areas of chaparral fires in central and southern California which had relatively heavy fuel loading.

On an annual basis, region wide and state level fire emissions of $\mathrm{CO}$ and $\mathrm{PM}_{2.5}$ were significant relative to emissions from non-fire sources (Sect. 4.4). Fire emissions were heavily concentrated both temporally and spatially. While fire emissions occurred on 1915 days (87\% of total days) during the study period, $13 \%$ of total emissions occurred on 10 days and $27 \%$ of total emissions occurred on 30 days. 

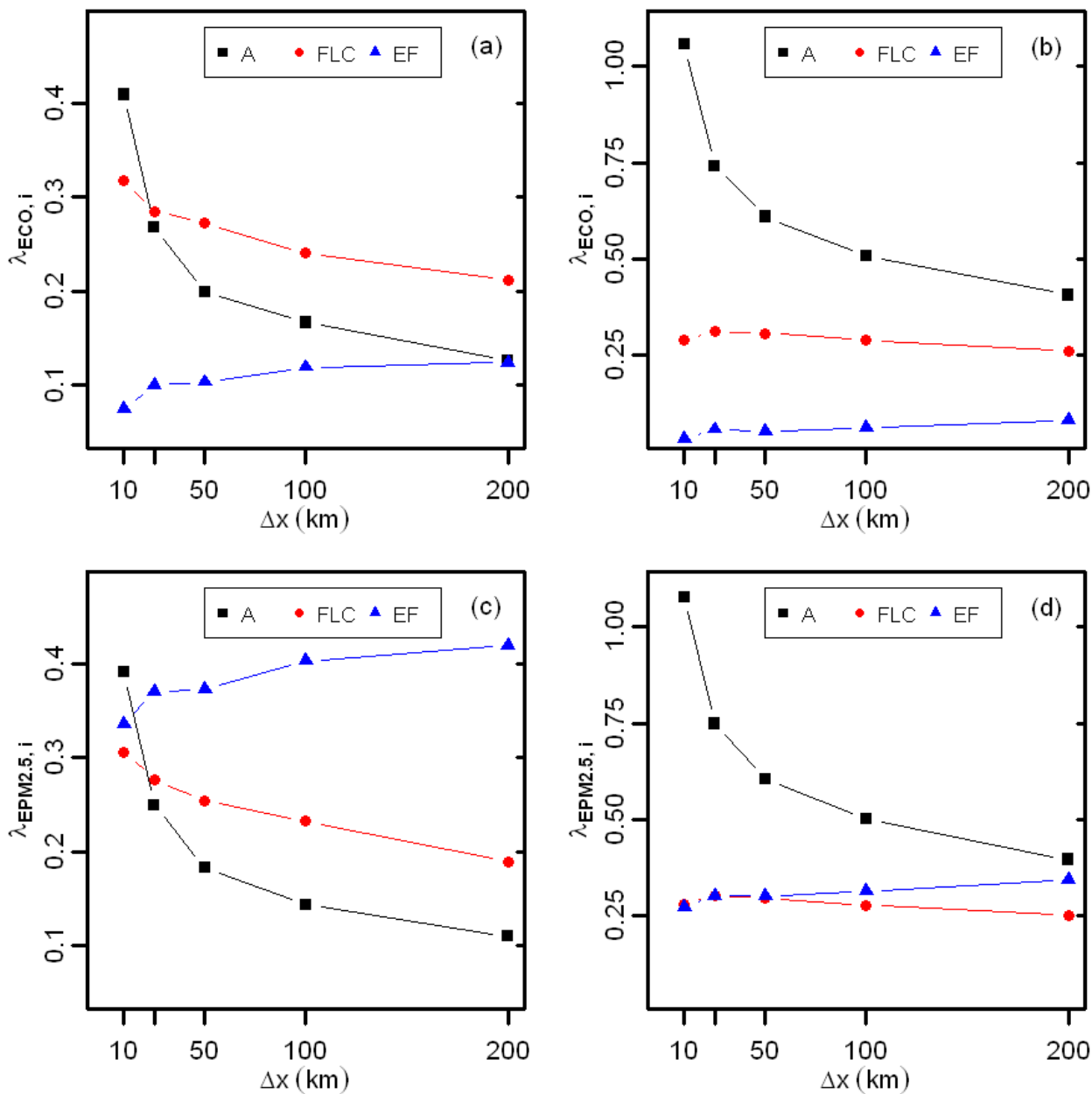

Fig. 11. Sensitivity of $\tilde{u}_{\mathrm{ECO}}\left(\lambda_{\mathrm{ECO}, i}\right)$ and $\tilde{u}_{\mathrm{EPM}_{2.5}}\left(\lambda_{\mathrm{EPM}_{2.5}, i}\right)$ to $1 \sigma$ absolute uncertainties in the emission model components $(i=\mathrm{A}, \mathrm{FLC}$, $\mathrm{EF}$, Table 1). $\tilde{u}_{\mathrm{EX}}\left(\mathrm{X}=\mathrm{CO}\right.$ or $\left.\mathrm{PM}_{2.5}\right)$ is our figure of merit and is defined such that $50 \%$ of total emissions (EX)are estimated with an uncertainty less than $\tilde{u}_{\mathrm{EX}}$ (Sect. 2.2.7). Sensitivities are plotted versus $\Delta x$ for temporal aggregation of $\Delta t=30$ day (panels (a) and (c)) and $\Delta t=1$ day (panels (b) and (d)).

Table 3. Annual sums of state level fuel consumption estimates (Gg dry vegetation $\mathrm{yr}^{-1}$ ) over 2003-2008.

\begin{tabular}{|c|c|c|c|c|c|c|c|c|}
\hline State & 2003 & 2004 & 2005 & 2006 & 2007 & 2008 & Total & Contribution $^{\mathrm{b}}$ \\
\hline AZ & 1027 & 711 & 932 & 536 & 356 & 277 & 3839 & $3.2 \%$ \\
\hline $\mathrm{CA}$ & 7685 & 1808 & 1292 & 4917 & 8882 & 4477 & 29060 & $24.3 \%$ \\
\hline $\mathrm{CO}$ & 411 & 277 & 338 & 256 & 166 & 419 & 1867 & $1.6 \%$ \\
\hline ID & 2366 & 214 & 3212 & 4096 & 15075 & 776 & 25738 & $21.5 \%$ \\
\hline MT & 8065 & 402 & 980 & 6991 & 9348 & 1075 & 26861 & $22.5 \%$ \\
\hline NM & 742 & 500 & 412 & 445 & 207 & 393 & 2699 & $2.3 \%$ \\
\hline NV & 84 & 151 & 926 & 1779 & 1177 & 565 & 4681 & $3.9 \%$ \\
\hline OR & 1714 & 321 & 791 & 1937 & 1976 & 831 & 7569 & $6.3 \%$ \\
\hline UT & 349 & 237 & 292 & 309 & 793 & 79 & 2059 & $1.7 \%$ \\
\hline WA & 1637 & 428 & 592 & 4324 & 521 & 350 & 7853 & $6.6 \%$ \\
\hline WY & 1722 & 139 & 180 & 2241 & 1097 & 1859 & 7239 & $6.1 \%$ \\
\hline Total $^{\mathrm{a}}$ & $26279 \pm 27 \%$ & $5292 \pm 36 \%$ & $9766 \pm 31 \%$ & $27119 \pm 27 \%$ & $39710 \pm 19 \%$ & $11240 \pm 47 \%$ & $119406 \pm 27 \%$ & $100.0 \%$ \\
\hline
\end{tabular}

${ }^{\mathrm{a}}$ Uncertainties are $1 \sigma$ (see Sect. 2.2.4). ${ }^{\mathrm{b}}$ Contribution is the percent contribution of estimated fuel consumption in each state to the 6 year total. 
During these high activity episodes $\mathrm{CO}$ and $\mathrm{PM}_{2.5}$ emissions from fires dominated other emission sources and likely played a significant role in regional air quality.

\subsection{Uncertainty}

The fractional uncertainties in $\mathrm{CO}$ and $\mathrm{PM}_{2.5}$ emissions ( $u_{\mathrm{ECO}}$ and $u_{\mathrm{EPM}_{2.5}}$ ) decreased with increasing scale due to the concurrent reduction of the relative error in the burned area estimates. As the scale of aggregation increases the characteristic burned area of the elements increases as well and there is a corresponding decrease of the relative error in the burned area estimate. This dwindling $u_{\mathrm{A}}$ with increasing scale results in a reduction of the relative uncertainty in ECO and $\mathrm{EPM}_{2.5}$.

At scales relevant to regional air quality modeling $(\Delta x=$ $10 \mathrm{~km}, \Delta t=1$ day) WFEI estimates $50 \%$ of total ECO with an uncertainty $>133 \%$ and a like fraction of total $\mathrm{EPM}_{2.5}$ is estimated with an uncertainty $>146 \%$. Uncertainty in the burned area $\left(u_{\mathrm{A}}\right)$ drives the emission uncertainties at this scale and reducing $u_{\mathrm{A}}$ would be the most effective approach for improving the emission estimates for regional modeling. WFEI employs a burned area mapping algorithm designed for near-real-time applications, such as supporting air quality forecasting. Replacing this algorithm with a more sophisticated, non-real-time burned area mapping method, for example a differenced normalized burn ratio (dNBR) method, may reduce the uncertainty in WFEI for retrospective modeling studies. However, such methods are generally not suitable for time sensitive applications such as air quality forecasting or the planning of scientific missions with research flights during field experiments.

The uncertainty in WFEI ECO and EPM 2.5 is significantly reduced at the scale of global modeling applications $(\Delta x=$ $100 \mathrm{~km}, \Delta t=30$ day). Fifty percent of total emissions are estimated with an uncertainty $<50 \%$ for $\mathrm{CO}$ and $<64 \%$ for $\mathrm{PM}_{2.5}$. At this scale, the uncertainty in ECO is most sensitive to uncertainties FLC, while the uncertainty in EF drives the uncertainty in $\mathrm{PM}_{2.5}$ emissions. Refinement of $\mathrm{EFPM}_{2.5}$, perhaps through the use of ecosystem specific EF rather than the simple cover type delineation currently implemented in WFEI, could reduce EF uncertainty and efficiently improve $\mathrm{EPM}_{2.5}$. Compared to EFPM 2.5 , EFCO is much better characterized and reductions in $u_{\mathrm{FLC}}$ would have the greatest impact on uncertainty in ECO at this scale.

\subsection{Comparison against other BB emission inventories}

\subsubsection{Relative uncertainties}

The published biomass burning emission inventories (BB EI) that cover our study region and time period include agricultural burning and are reported for broader domains (e.g. CONUS or North America) and therefore direct comparison with the emissions estimates presented here is not possible.
(In Sect. 4.4 we do compare WFEI to a state level emission inventory). However, a few studies report quantitative uncertainty estimates for regional emissions that may be compared with the uncertainties estimated in our study. The Global Fire Emission Database version 3 (GFED3) (van der Werf et al., 2010 ) is the only BB EI coinciding with our study region and period which provides a quantitative uncertainty estimate. In the supplementary material, van der Werf et al. (2010) report $1 \sigma$ relative uncertainties in the annual $\mathrm{C}$ emissions (EC; $\mathrm{EC}=\mathrm{ECO}_{2}+\mathrm{ECO}+\mathrm{ECH}_{4}$ ) for CONUS (which they label as Temperate North America) of $u_{\mathrm{EC}} \sim 21 \%$. Neglecting uncertainties regarding the small fraction of combusted biomass $\mathrm{C}$ that is emitted in other forms (e.g., NMOC and carbonaceous aerosol), we compare their $u_{\mathrm{EC}}$ with our relative uncertainty in annual fuel consumed (Table 3 ). In most years, the uncertainty in our estimate is larger, the ratio of uncertainties (ours/van der Werf) varies from 0.9-2.4. The sizeable difference in uncertainty estimates results from the large uncertainty we have ascribed to our fuel loading and fuel consumption. The uncertainty in our FLC is $19 \%-47 \%$ and accounts for virtually all of the uncertainty in the annual, domain wide total fuel consumption estimates (Table 3). French et al. (2004) reported annual BB carbon emissions for boreal Alaska with $u_{\mathrm{EC}}$ estimated as 23 to $27 \%$, again about half the uncertainty we estimate for WFEI. The African BB EI published by Liousse et al. (2010) reports a general inventory relative uncertainty of $57 \%$, roughly comparable to the uncertainty in annual, domain wide $\mathrm{EPM}_{2.5}$ for WFEI. Jain (2007) estimated the relative uncertainty in their BB EI's CO emitted was $75 \%$ for the US and Canada in 2000. The large uncertainty in ECO reported by Jain (2007), about twice that in the current study, reflects the large relative uncertainty the author assigned to the burned area for North America. Jain (2007) used a $u_{\mathrm{A}}$ of $45 \%$ which we believe is large and may not capture the decrease in relative error with increasing area burned that is reported both here and in two previous studies that used satellite data for burned area (Giglio et al., 2010; Urbanski, 2009a).

\subsubsection{Sensitivity}

Several published BB EI include a cursory assessment of their inventory's sensitivity to fuel loading and fuel consumption. Because the estimated uncertainty in our annual, domain wide FLC (19-47\%; Fig 9a) was based on different combinations of mapped fuel loadings and fuel consumption models (Sect. 2.2.2.2) we can gain some insight by comparing our results with similar analysis in other studies. Zhang et al. (2008) developed a near-real-time BB emission model for CONUS. The model combines burned area information from the GOES WF_ABBA and fuel loading maps based on their MODIS Vegetation Property-based Fuel Systems (MVPFS) to estimate $\mathrm{PM}_{2.5}$ emissions. They assessed the sensitivity of their model emissions to fuel loading by running their algorithm with a $1 \mathrm{~km}$ FCCS map (different from 
the mapping used in our study) substituted for MVPFS. The annual CONUS wide estimates of $\mathrm{EPM}_{2.5}$ based on the two fuel loading maps differed by $-16 \%$ to $+17 \%$ over 2002 2005. This sensitivity of emissions on mapped fuel loading is considerably less than that observed in the current study, where independent of fuel consumption model, the choice of mapped fuel loading resulted in a $+37 \%$ to $+189 \%$ difference in fuel consumed (which is proportional to $\mathrm{EPM}_{2.5}$ ).

The global model Fire Inventory from NCAR version 1.0 (FINNv1) (Wiedinmyer et al., 2011) estimates daily, BB emissions with a $1 \mathrm{~km}$ resolution using burned area derived from MODIS active fire detections. The model is designed to support both near-real-time and retrospective modeling applications. A detailed assessment of the model's uncertainty is not given, but the authors did explore the sensitivity of the emission model to the choice in land cover maps. Changing the FINNv1 land cover map resulted in a $20 \%$ change in CO emissions in 2006 across CONUS, Mexico, and Central America. Similar results for land cover map substitution were reported for the precursor model of FINNv1 (Wiedinmyer et al., 2006). In both studies, the substitution employed the same the fuel loading model and fuel consumption algorithm, and thus provides information only on the sensitivity to the mapping of fuel models. This aspect of uncertainty was not specifically addressed in our study.

\subsection{Comparison versus 2005 national emission inventory}

We compare our emission estimates with the United States Environmental Protection Agency (USEPA) National Emission Inventory (NEI) 2005 v2 (USEPA, 2011). NEI 2005 v2 includes annual, state level estimates of $\mathrm{CO}$ and $\mathrm{PM}_{2.5}$ emissions for various sources including wildfires and prescribed burning. In the following discussion NEI 'WF emissions' refers to the sum of emissions from wildfire and prescribed burning reported in NEI 2005 v2 and excludes agricultural burning. "Non-WF emissions" refers to emission estimates from NEI 2005 v2 for all non-WF sources (agriculture, dust, non-WF fire, fuel combustion, industrial processes, transportation, solvent, and miscellaneous). Figure 12 compares state level NEI WF emission estimates with our 2005 WFEI. In most states, the NEI WF emission estimates exceeded the WFEI, and the NEI 11 state sums were $119 \%$ larger for ECO $\left(1698 \mathrm{Gg} \mathrm{CO} \mathrm{yr}^{-1}\right.$ vs. $788 \mathrm{Gg} \mathrm{CO} \mathrm{yr}^{-1}$ ) and $28 \%$ larger for $\mathrm{EPM}_{2.5}\left(147 \mathrm{Gg} \mathrm{PM}_{2.5} \mathrm{yr}^{-1}\right.$ vs. $117 \mathrm{Gg} \mathrm{PM}_{2.5} \mathrm{yr}^{-1}$ ). Due to the complex methodology and methods behind the NEI it is difficult to identify the causes of the discrepancy. WFEI does not include canopy fuels and this likely contributes to the difference. Additionally, , the significant differential in the ECO and $\mathrm{EPM}_{2.5}$ disparities indicates that the choice of EFs plays a role.
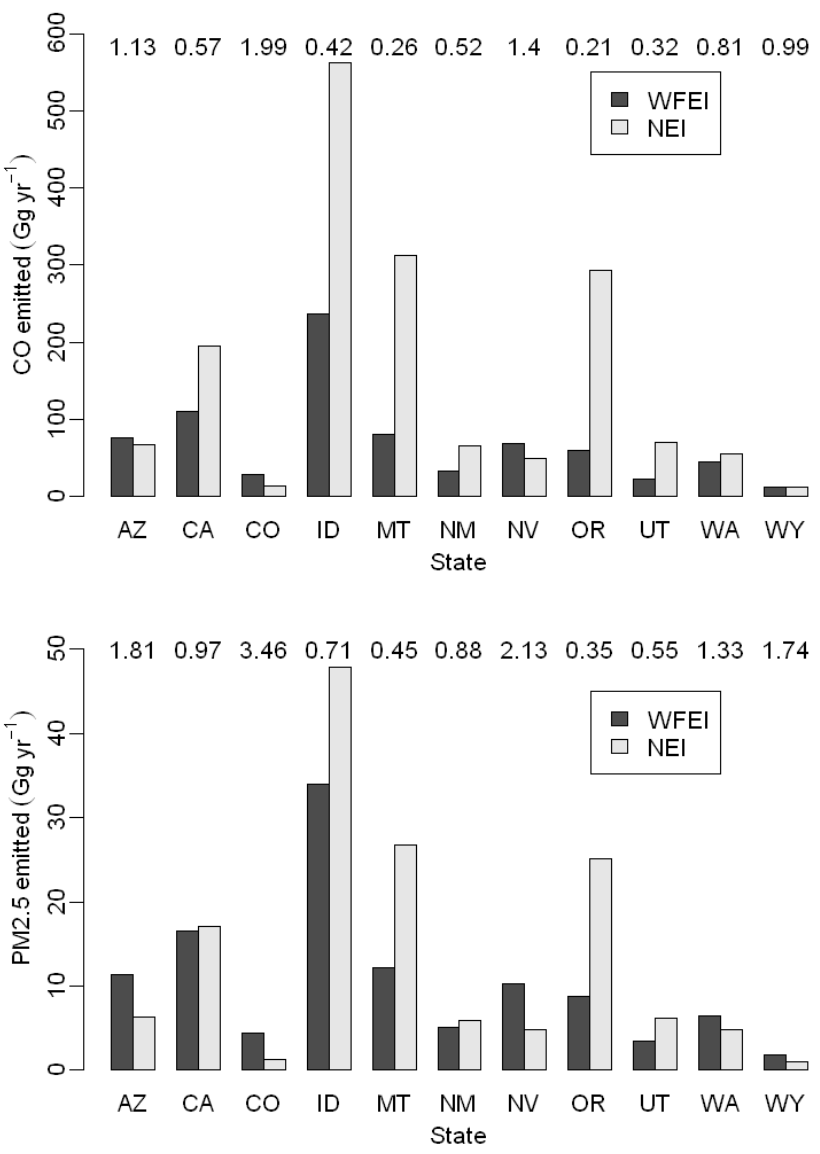

Fig. 12. State level, 2005 wildland fire emissions from WFEI and NEI 2005 v2. Bars show annual sums of emitted CO (top panel) or emitted $\mathrm{PM}_{2.5}$ (bottom panel) in units of $\mathrm{Gg} \mathrm{yr}^{-1}$. The numbers centred above each pair of bars and running across the top of each plot provide the WFEI to NEI emission ratios.

The importance of WF emissions, as estimated by WFEI, is examined with respect to other sources. We use "total emissions" to refer to the sum of the NEI non-WF emissions and WF emissions estimated using WFEI. The following analysis assumed annual non-WF emissions were constant over 2003-2008 and used NEI 2005 non-WF emissions. Therefore the inter-annual variability in the emission ratios (WF/total) results strictly from variability in fire activity. Annually, across the western United States, WF emissions were 3-20\% of total ECO and 8-39\% of total EPM 2.5 . In all years the WF/total emission ratio for $\mathrm{PM}_{2.5}$ was larger than that for CO. Figure 13 shows the annual, state level ratios of WF emissions to total emissions. The relative importance of WF emissions was greatest in Idaho and Montana where fires accounted for a majority of ECO and $\mathrm{EPM}_{2.5}$ during active fire years. In most states, WF EPM 2.5 was significant during active fires years comprising $30-40 \%$ of total emissions. Even in California, a state with large non-WF pollution sources, WF contributed $20 \%$ or more of total $\mathrm{EPM}_{2.5}$ in most years. 
Table 4. Annual sums of state level CO emission estimates $\left(\mathrm{Gg} \mathrm{CO} \mathrm{yr}^{-1}\right)$ over 2003-2008.

\begin{tabular}{lrrrrrrrr}
\hline State & 2003 & 2004 & 2005 & 2006 & 2007 & 2008 & Total $^{\text {Contribution }}$ \\
\hline AZ & 88 & 61 & 77 & 46 & 31 & 24 & 327 & $3.4 \%$ \\
CA & 587 & 143 & 106 & 386 & 696 & 381 & 2298 & $24.0 \%$ \\
CO & 35 & 23 & 29 & 21 & 14 & 34 & 156 & $1.6 \%$ \\
ID & 185 & 17 & 244 & 311 & 1177 & 61 & 1996 & $20.9 \%$ \\
MT & 662 & 33 & 81 & 555 & 794 & 80 & 2204 & $23.1 \%$ \\
NM & 64 & 43 & 35 & 39 & 18 & 34 & 233 & $2.4 \%$ \\
NV & 7 & 12 & 76 & 123 & 83 & 43 & 344 & $3.6 \%$ \\
OR & 143 & 26 & 62 & 149 & 156 & 67 & 602 & $6.3 \%$ \\
UT & 29 & 20 & 24 & 25 & 63 & 7 & 168 & $1.8 \%$ \\
WA & 134 & 35 & 46 & 366 & 40 & 27 & 647 & $6.8 \%$ \\
WY & 136 & 10 & 14 & 182 & 88 & 158 & 587 & $6.1 \%$ \\
\hline Total & $2116_{-31 \%}^{+33 \%}$ & $436_{-40 \%}^{+41 \%}$ & $788_{-35 \%}^{+37 \%}$ & $2084_{-30 \%}^{+35 \%}$ & $3107_{-24 \%}^{+28 \%}$ & $923_{-49 \%}^{+51 \%}$ & $9455_{-31 \%}^{+35 \%}$ & $100.0 \%$ \\
\hline
\end{tabular}

${ }^{\mathrm{a}}$ Uncertainties are $1 \sigma$ (see Sect. 2.2.6). ${ }^{\mathrm{b}}$ Contribution is the percent contribution of estimated ECO in each state to the 6 year total.

Table 5. Annual sums of state level $\mathrm{PM}_{2.5}$ emission estimates $\left(\mathrm{Gg} \mathrm{PM}_{2.5} \mathrm{yr}^{-1}\right)$ over 2003-2008.

\begin{tabular}{lrrrrrrrr}
\hline State & 2003 & 2004 & 2005 & 2006 & 2007 & 2008 & Total & Contribution $^{\mathrm{b}}$ \\
\hline AZ & 13 & 9 & 12 & 7 & 5 & 4 & 50 & $3.5 \%$ \\
CA & 85 & 21 & 16 & 56 & 102 & 58 & 337 & $23.9 \%$ \\
CO & 5 & 4 & 4 & 3 & 2 & 5 & 24 & $1.7 \%$ \\
ID & 27 & 2 & 35 & 45 & 172 & 9 & 290 & $20.6 \%$ \\
MT & 99 & 5 & 12 & 82 & 120 & 11 & 329 & $23.3 \%$ \\
NM & 10 & 7 & 5 & 6 & 3 & 5 & 36 & $2.5 \%$ \\
NV & 1 & 2 & 11 & 17 & 12 & 6 & 49 & $3.4 \%$ \\
OR & 22 & 4 & 9 & 21 & 23 & 10 & 89 & $6.3 \%$ \\
UT & 4 & 3 & 4 & 4 & 9 & 1 & 25 & $1.8 \%$ \\
WA & 20 & 5 & 7 & 55 & 6 & 4 & 97 & $6.9 \%$ \\
WY & 20 & 1 & 2 & 27 & 13 & 24 & 87 & $6.2 \%$ \\
\hline Total $^{\mathrm{a}}$ & $313_{-33 \%}^{+49 \%}$ & $65_{-42 \%}^{+56 \%}$ & $117_{-33 \%}^{+50 \%}$ & $302_{-33 \%}^{+50 \%}$ & $454_{-28 \%}^{+43 \%}$ & $138_{-50 \%}^{+64 \%}$ & $1389_{-34 \%}^{+49 \%}$ & $100.0 \%$ \\
\hline
\end{tabular}

${ }^{\mathrm{a}}$ Uncertinaties are $1 \sigma$ (see Sect. 2.2.6). ${ }^{\mathrm{b}}$ Contribution is the percent contribution of estimated $\mathrm{EPM}_{2.5}$ in each state to the 6 year total.

Assuming non-WF emissions were distributed evenly across the months of the year, $\mathrm{EPM}_{2.5}$ from WF in July, August, and September of 2006 and 2007 accounted for more than half of domain wide emissions in each month. In 2003 and 2007, intense fire seasons in southern California resulted in $\mathrm{EPM}_{2.5}$ from WF accounting for $56 \%$ and $47 \%$ of total domain wide emissions during October.

\subsection{Future developments}

Our assessment of WFEI neglected, in some cases necessarily, several key aspects of the model uncertainty related to fuel loading, fuel consumption, and EFs. In the case of fuel loading and fuel consumption we lack adequate error information regarding input data. Due to the lack of appropriate fuels data, a statistical sample of the fuel loading pre- diction error could not be used to quantify the uncertainty in the FLM and FCCS fuel loadings. Without data for a true error assessment, we were limited to the less than optimal approach of taking the range of FLM and FCCS as an estimate of the uncertainty. Furthermore, we were unable to assess the mapping error and could not include this source of uncertainty in our analysis. We anticipate future access to a large fuel loading dataset that will enable a true quantification of the error in the mapping of the FLM and FCCS and their fuel loading prediction error. The acquisition of an appropriate fuel loading data set will enable a true quantification of the errors in each fuel loading model and their mapping. Such an effort would provide a proper estimation of the true uncertainty in both the FCCS and FLM mapped fuel loads and possibly identify which product is most accurate over different regions of the domain. While determining the uncertainty 

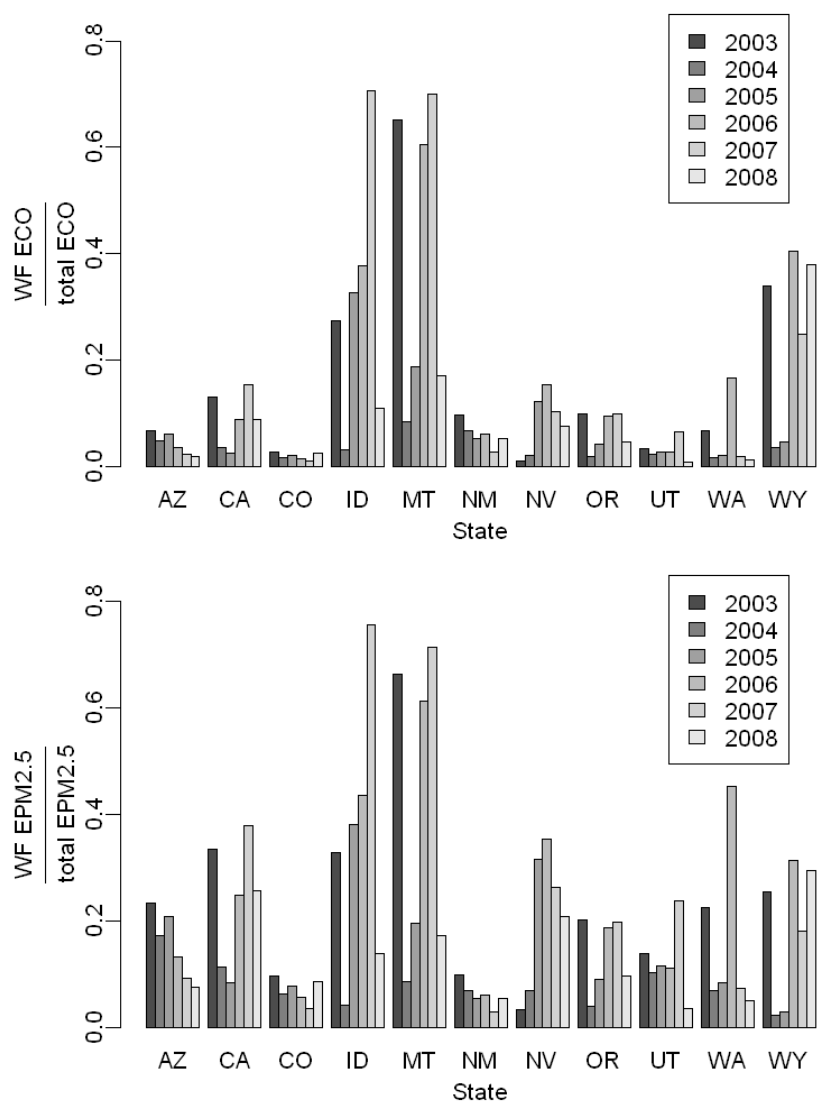

Fig. 13. Annual, state level ratio of WF emissions (from WFEI) to total emissions (WF + non-WF NEI). Top panel is ECO ratio and bottom panel is $\mathrm{EPM}_{2.5}$ ratio.

in this manner would provide a more robust result, the values of $u_{\text {FLC }}$ would not necessarily be reduced relative to those estimated with the ensemble approach applied in this study.

In addition to better characterizing the uncertainty of WFEI, the magnitude of the uncertainties may be reduced by improving the model components. The burned area mapping currently employed in WFEI was designed to provide near-real-time emission estimates for operational applications such as air quality forecasting. For regional scale applications not requiring near-real time data, $u_{\mathrm{A}}$ and hence $\tilde{u}_{\mathrm{ECO}}$ and $\tilde{u}_{\mathrm{EPM}_{2.5}}$, could be reduced by implementing a differenced burn ratio method for mapping burned area (e.g. Giglio et al., 2009). This change in WFEI would be particularly beneficial for regional scale modeling applications where the uncertainty in emissions is dominated by $u_{\mathrm{A}}$. Examples of such applications are retrospective atmospheric chemical transport model simulations that quantify the contribution of wildfires to air quality or investigate the role of fires in regional climate forcing.

Reducing the uncertainty in $\mathrm{EFPM}_{2.5}$ would reduce $\tilde{u}_{\mathrm{EPM}_{2.5}}$, especially for global modeling applications. In general, employing ecosystem specific EFs rather than the broad forest or non-forest classification used in this study may significantly reduce $\tilde{u}_{\mathrm{EX}}$. While $\tilde{u}_{\mathrm{ECO}}$ was relatively insensitive to $u_{\mathrm{EFCO}}$, this will not be the case when the model is expanded to include the emissions of additional compounds which have less well characterized EF (e.g., NMOC). WFEI is designed to include the broad of range compounds (e.g. NMOC, nitrogen oxides) emitted by WF (see Akagi et al., 2011). The emission intensities of most compounds vary with combustion phase (flaming or smoldering). Fuel type and fuel condition, fire type, and meteorological conditions all impact the characteristics of fuel combustion (Anderson, 1983; Albini, 1976; Rothermel, 1972). Modified combustion efficiency (MCE) is a measure of the relative contributions of flaming and smoldering combustion, and the emission intensities of many compounds are proportional to MCE (see for example Burling et al., 2010). The dataset used to provide EFCO and $\mathrm{EFPM}_{2.5}$ includes MCE and can be used to estimate EFs for a wide range of NMOC using NMOC-MCE relationships in the literature.

However, our study used an emission factor dataset that was heavily biased towards prescribed fires, the combustion characteristics (and hence the MCE) of which may not be representative of the wildfires which dominate emissions in the western United States. This issue is critical, because many of the highly reactive NMOC emitted by WFs are a strong function of MCE. Sufficient emission data are not currently available to characterize the MCE typical of wildfires in the dominant vegetation types of the western United States. NMOC emission estimates based on currently available MCE data may result in a significant systematic error. Due to the lack of existing wildfire data this source of error could not be addressed in our study. However, an ongoing field research project (JFSP, 2008) is collecting emission measurements from wildfires in the western United States and in the near future we will use these data to update WFEI with improved EFs, including MCE based EFs for NMOC.

While WFEI was assessed only for the western United States in this study, it is designed for CONUS. A future assessment of WFEI will include coverage for all of CONUS.

\section{Conclusions}

We have presented a WF emission inventory (WFEI) for the western United States from 2003 to 2008. The emission model used to produce WFEI may be used to forecast and evaluate the impact of wildfires on regional air quality. WFEI is based on our MODIS Direct Broadcast burned area mapping algorithm that enables near-real-time emission estimates that are needed to support air quality forecasting. The uncertainty in the inventory estimates of $\mathrm{CO}$ and $\mathrm{PM}_{2.5}$ emissions have been quantified across spatial and temporal scales relevant to regional and global modeling applications. The sensitivity of the WFEI uncertainties to emission model components was evaluated to identify algorithm modifications 
likely to be most effective for reducing the inventory uncertainty for various applications.

Wildland fires in the western United States burned an average of $10742 \mathrm{~km}^{2} \mathrm{yr}^{-1}$ from 2003-2008, with extremes of $3622 \mathrm{~km}^{2}$ in 2004 and $19352 \mathrm{~km}^{2}$ in 2007 . The estimated annual $\mathrm{CO}$ emitted by these fires ranged from $436 \mathrm{Gg} \mathrm{yr}^{-1}$ in 2004 to $3107 \mathrm{Gg} \mathrm{yr}^{-1}$ in 2007 . The uncertainty in annual CO emitted was $28 \%$ to $51 \%$. The estimated annual $\mathrm{PM}_{2.5}$ emissions ranged from $65 \mathrm{Gg} \mathrm{yr}^{-1}$ (2004) to $454 \mathrm{Gg} \mathrm{yr}^{-1}$ (2007). The uncertainty in annual $\mathrm{EPM}_{2.5}$ varied from $43 \%$ to $64 \%$. Annual fire emissions were significant compared to other emission sources as estimated in the USEPA NEI 2005 v2. In the peak fire year of 2007, domain wide total fire emissions were $\sim 20 \%$ of total ECO and $\sim 39 \%$ of total $\mathrm{EPM}_{2.5}$. During the months with the greatest fire activity, fires accounted for the majority of $\mathrm{CO}$ and $\mathrm{PM}_{2.5}$ emitted across the entire study region.

Uncertainty in ECO and EPM25 varied strongly with the spatial and temporal scale because the fractional uncertainty in burned area decreased rapidly with increasing $\Delta x$ and/or $\Delta t$. Sensitivity of the uncertainty in ECO and $\mathrm{EPM}_{2.5}$ to the emission model components depended on scale. At scales relevant to regional modeling applications ( $\Delta x=10 \mathrm{~km}, \Delta t=1$ day) WFEI estimated $50 \%$ of total ECO with an uncertainty $<133 \%$ and half of total $\mathrm{EPM}_{2.5}$ was estimated with an uncertainty $<146 \%$. Uncertainty in the burned area $\left(u_{\mathrm{A}}\right)$ dominated the emission uncertainties at this scale and reducing $u_{\mathrm{A}}$ would be the most effective approach for improving emission estimates for regional modeling. WFEI employs a burned area mapping algorithm designed for near-real-time applications, such as supporting air quality forecasting. Replacing this algorithm with a more sophisticated, "non-operational" burned area mapping method may reduce the uncertainty in WFEI for retrospective modeling studies.

The uncertainty in WFEI ECO and EPM $_{2.5}$ was significantly less at the scale of global modeling applications $(\Delta x=$ $100 \mathrm{~km}, \Delta t=30$ day). Fifty percent of total emissions were estimated with an uncertainty $<50 \%$ for $\mathrm{CO}$ and $<64 \%$ for $\mathrm{PM}_{2.5}$. At this scale, the uncertainty in ECO was most sensitive to uncertainties in fuel loading consumed (FLC) while the uncertainty in EF dominated the $\mathrm{EPM}_{2.5}$ uncertainty. Refinement of $\mathrm{EFPM}_{2.5}$, perhaps through the use of ecosystem specific EF, rather than the simple cover type delineation currently implemented in WFEI, could reduce EF uncertainty and efficiently improve $\mathrm{EPM}_{2.5}$. Compared to $\mathrm{EFPM}_{2.5}$, EFCO is much better characterized and reductions in $u_{\mathrm{FLC}}$ would have the greatest impact on uncertainty in ECO at this scale.

Our analysis indicates that "headline", aggregate uncertainties (e.g. annual, CONUS) reported for BB EI may be misleading for evaluating and interpreting the results of modeling applications that employ the emission estimates. Ideally, BB EI should be evaluated across the scales for which they are intended to be used and the EI uncertainty should be reported at these scales. We employed a figure of merit, which we called the half mass uncertainty, which is useful for evaluating uncertainty in the EI across spatio-temporal scales. However, estimating uncertainties in BB EI is difficult. Often the appropriate data is not available to fully evaluate all components of emission models. Lacking satisfactory data, unorthodox methods are often required to estimate uncertainty, and even with significant effort the resulting uncertainty estimates may themselves be fairly uncertain. As a result, many BB EI report only annual uncertainties for large regions and provide only a limited sensitivity analysis. Nevertheless, we believe that using a figure of merit similar to the half mass uncertainty employed in our study to evaluate the uncertainty in BB EI across pertinent spatio-temporal scales would provide modelers and policy makers with improved guidance on the use of the inventories as well as facilitate the development of improved BB EI with better characterized uncertainties.

\section{Appendix A}

\section{Evaluation of MODIS burned area mapping algorithm}

In this study we defined the burned area uncertainty as the error cone expected to contain approximately $68 \%$ of the "ground truth" burned area values of which the MODIS burned area mapping algorithm is a measurement. This definition of uncertainty provides a coverage comparable to that of a standard uncertainty for normally distributed data (i.e. coverage of $\sim 68 \%$ for $1 \sigma$ ). Following Urbanski et al. (2009a) and Giglio et al. (2010), we employed an empirical error estimation approach to identify this error cone. The empirical error function (Eq. A1) describes the uncertainty in the MODIS burned area measurement as a function of burned area. In Eq. (A1), $x$ is the $25 \mathrm{~km} \times 25 \mathrm{~km}$ gridded MODIS burned area measurement and $\sigma^{2}$ is the variance in of the error in $\mathrm{x}$.

$\sigma^{2}=\mathrm{bx}$

A total of $46325 \mathrm{~km} \times 25 \mathrm{~km}$ grid cells were used to evaluate Eq A1. Details of the data used and its preparation are provided in Sect. 2.2.3. The coefficient in Eq. (A1) was evaluated as follows: 1) the MODIS burned area (x) and measurement error (=MTBS "ground truth" $-\mathrm{x}$ ), ordered by the value of $\mathrm{x}$, were assigned to 4310-member bins, 2) the Winsorized variance $($ trim $=0.1)$ of the error $\left(\sigma_{\text {block }}^{2}\right)$ and the mean of $x$ $\left(x_{\text {block}}\right)$ were calculated for blocks of $30 \mathrm{x}$-error data point pair using a gliding window of 3 bins, providing a total of 41 evaluation blocks, 3) $\sigma_{\text {block }}^{2}$ was regressed against $x_{\text {block }}$ using ordinary least squares regression to estimate the slope, b. The fit of $\sigma_{\text {block }}^{2}$ is shown in Fig. A1 and the value of the slope and fit statistics are provided in the Fig. A1 caption. 


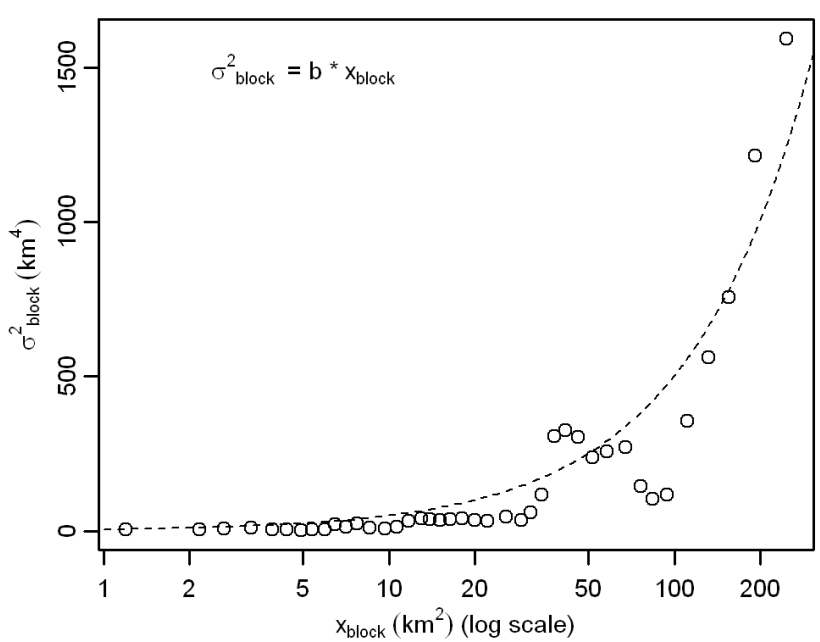

Fig. A1. Empirical error function for MODIS burned area measurement. The $\mathrm{x}$-axis is the average MODIS measured burned area for blocks of 30 grid cells $(25 \mathrm{~km} \times 25 \mathrm{~km})$ in log scale. Tthe y-axis is the variance of the measurement error for each block. The analysis used 41 blocks. Ordinary least squares regression with the intercept forced to zero yielded a coefficient value of $b=5.03 \mathrm{~km}^{2}$ with a coefficient of determination of $r^{2}=0.87$.

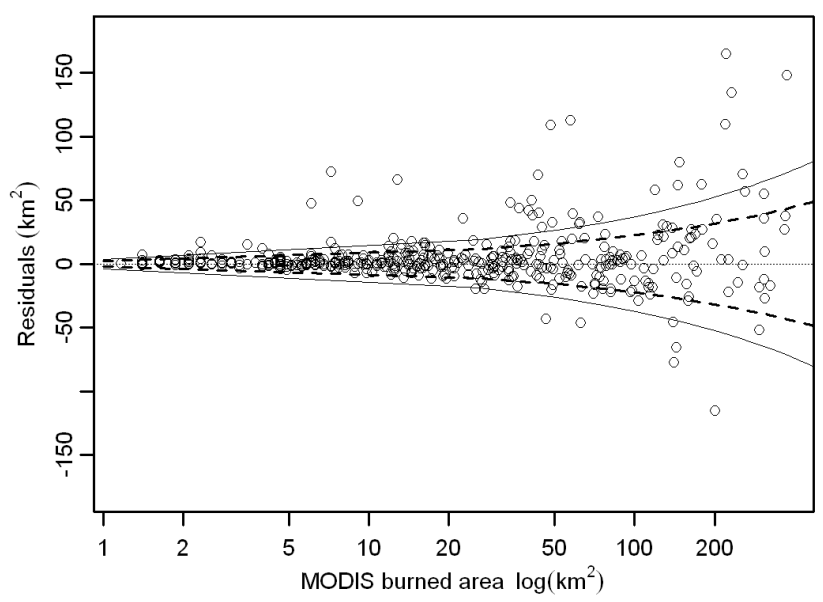

Fig. A2. Plot of burned area residuals (residuals = MTBS "ground truth" - MODIS burned area) versus the burned area (open circles). The $\mathrm{x}$-axis is log scale. The dashed (solid) curve is $\pm 1 \sigma$ $( \pm 1.65 \sigma)$ as estimated with the empirical error function, Eq. (A1) with $\mathrm{b}=5.03 \mathrm{~km}^{2}$. The $1 \sigma(1.65 \sigma)$ uncertainty envelopes $70 \%$ $(87 \%)$ of the residuals.

The error predicted with Eq. (A1) $\left(\sigma_{\mathrm{A}}\right)$ provides a meaningful measure of the uncertainty in the MODIS burned area across the span of "ground truth" burned area values. The empirical uncertainty satisfies our uncertainty definition by providing coverage comparable to that of a standard uncertainty for normally distributed data (i.e. coverage of $\sim 68 \%$ for $1 \sigma$, and $\sim 90 \%$ for $1.65 \sigma$ ) (Fig. A2). Seventy percent of the "ground truth" burned area values fall within the uncer- tainty bounds and when a coverage factor of 1.65 is applied, $87 \%$ of the "ground truth" values are enveloped by the resulting uncertainty bounds (Fig. A2). In addition to providing the intended coverage, the empirical uncertainty cone captures the variability of the measurement error across the observations. The error equation was applied to the aggregated MODIS burned area data for all temporal and spatial scales $\left(g_{\Delta x, \Delta t}(k, t)\right)$, providing the $\sigma(\mathrm{A})$ describing the error distribution used in the Monte Carlo simulations (Sect. 2.2.3).

\section{Appendix B}

\section{Supplemental FLM}

This appendix describes the six herbaceous and shrub fuel loading models that were constructed to supplement the FLM. While these six fuel loading models have been labeled "supplemental FLM", they were developed using a philosophy very different from that embodied in the FLM. The supplemental FLM fuelbeds are organized according to vegetation type while the FLM fuelbeds are classified based on the anticipated fire effects. The development of the supplemental FLM can be summarized as follows:

1. Identify burned pixels with a non-forest FLM code (39\% of burned pixels in our study).

2. Assign the burned pixels with a non-forest FLM code the FCCS code of that pixel

3. Assign recoded FLM pixels a vegetation type based on the Society of Range Management (SRM) cover type associated with each FCCS fuelbed.

4. Generalize the SRM based vegetation types into six classes which serve as the supplemental FLM:

- Sage brush

- Generic interior shrub

- Generic interior grassland

- Coastal sage shrub

- Chamise chaparral

- Ceanothus mixed chaparral

5. Select sites from the Natural Fuels Photo Series to represent the 6 vegetation types

6. Create fuel loadings for the supplemental FLM using the median fuel loadings of the appropriate Natural Fuels Photo Series sites

Table B1 provides details of the data used to develop the supplemental FLM and Table B2 gives the supplemental FLM fuel loading values used in this study. 
Table B1. Supplemental FLM.

\begin{tabular}{|c|c|c|c|}
\hline Supplemental FLM & $\begin{array}{l}\text { Percent of } \\
\text { burned } \\
\text { pixels }\end{array}$ & Dominant FCCS fuelbed & $\begin{array}{l}\text { Natural Fuels Photo } \\
\text { Series* }\end{array}$ \\
\hline Sage brush & $69.2 \%$ & Sagebrush shrubland & $\begin{array}{l}\text { Vol. I SB03; } \\
\text { Vol. IV SWSB } 02- \\
\text { 11; Vol. X SG } \\
\text { 01-11; Vol. XI } \\
\text { EOSG 05-12 }\end{array}$ \\
\hline $\begin{array}{l}\text { Generic interior } \\
\text { shrubland }\end{array}$ & $2.5 \%$ & $\begin{array}{l}\text { Turbinella oak - Mountain } \\
\text { mahogany shrubland }\end{array}$ & $\begin{array}{l}\text { Vol. I WJ 01-03; } \\
\text { SB 01, 02, 04; } \\
\text { Vol. III GO 02; 03; } \\
\text { Vol. IV SWSB 01; } \\
\text { PJ 01-03; Vol. VII } \\
\text { MCS 10; Vol. XI } \\
\text { EOSG 02, } 04\end{array}$ \\
\hline $\begin{array}{l}\text { Generic interior } \\
\text { grassland }\end{array}$ & $12.8 \%$ & $\begin{array}{l}\text { Bluebunch wheatgrass - } \\
\text { Bluegrass grassland }\end{array}$ & $\begin{array}{l}\text { Vol. I BG 01-04; } \\
\text { Vol. XI EOSG 01, } \\
03\end{array}$ \\
\hline Coastal sage shrub & $1.1 \%$ & Coastal sage shrubland & Vol. IV CH 01-03 \\
\hline Chamise chaparral & $5.6 \%$ & $\begin{array}{l}\text { Chamise chaparral } \\
\text { shrubland }\end{array}$ & Vol. IV CH 04-09 \\
\hline $\begin{array}{l}\text { Ceanothus mixed } \\
\text { chaparral }\end{array}$ & $8.8 \%$ & $\begin{array}{l}\text { Scrub oak - Chaparral } \\
\text { shrubland }\end{array}$ & Vol. IV CH 10-16 \\
\hline
\end{tabular}

*References: Vol. I Ottmar et al. (1998), Vol. III Ottmar et al. (2000a), Vol. IV Ottmar et al. (2000b), Vol. VII Ottmar et al. (2004), Vol. X Ottmar et al. (2007b), Vol. XI Natural Fuels Digital Photo Series (2011).

Table B2. Supplemental FLM fuel loadings by fuel class.

\begin{tabular}{lrrrr}
\hline Supplemental FLM & \multicolumn{4}{c}{ Fuel Loading $\left(\mathrm{kg}\right.$ dry vegetation $\left.\mathrm{m}^{-2}\right)$} \\
\cline { 2 - 5 } & Litter & $\begin{array}{r}\text { Fine Woody } \\
\text { Debris }\end{array}$ & Herbaceous & Shrub \\
\hline Sage brush & 0.04 & 0.05 & 0.04 & 0.33 \\
Generic interior shrubland & 0.03 & 0.02 & 0.06 & 0.17 \\
Generic interior grassland & 0.07 & 0.0 & 0.24 & 0.0 \\
Coastal sage shrub & 1.66 & 0.0 & 0.0 & 2.15 \\
Chamise chaparral & 0.0 & 0.0 & 0.0 & 2.88 \\
Ceanothus mixed chaparral & 0.0 & 0.0 & 0.0 & 8.67 \\
\hline
\end{tabular}

\section{Appendix C}

\section{Potential emissions from canopy consumption}

The methods used in this study could not identify the occurrence of crown fire or reliably simulate canopy fuel consumption. However, it is informative to provide guidance on the potential magnitude of canopy fuel consumption relative to the consumption of surface and ground fuels that were considered in this study. Therefore, we conducted a simple calculation of canopy fuel consumption. Pre-fire canopy fuel loading for burned pixels was assigned using the mapped FCCS fuel loading models. It was then assumed that $25 \%$ of the canopy fuels were consumed at each burned pixel and emissions of $\mathrm{CO}$ and $\mathrm{PM}_{2.5}$ were calculated using the forest cover type $\mu_{\text {EFX }}$ from Table 1 ( $89 \mathrm{~g} \mathrm{CO} \mathrm{kg} \mathrm{dry} \mathrm{veg.} \mathrm{burned}{ }^{-1}$ and $13.3 \mathrm{~g} \mathrm{PM}_{2.5} \mathrm{~kg}$ dry veg. burned $^{-1}$ ). The choice of $25 \%$ for canopy fuel consumption is completely arbitrary. These calculations are presented for illustrative purposes and are not intended to be a "best estimate" of canopy fuel consumption. Results of this calculation and a comparison versus non-canopy emissions are provided in Table C1. Canopy fuel consumption of $25 \%$ results in emissions that are on the order of $10 \%$ of the base emissions (i.e. emissions from the consumption of from surface and ground fuels, Tables 4 and 5). Extrapolation of the results in Table $\mathrm{C} 1$ suggests that canopy consumption of $50 \%$ could increase the base emissions by close to $25 \%$. This exercise shows that consumption of canopy fuels will not dominate annual, domain wide emissions. However, canopy fuel consumption could make a non-negligible contribution to overall emissions. 
Table C1. Estimate of annual $\mathrm{CO}$ and $\mathrm{PM}_{2.5}$ emitted from $25 \%$ consumption of forest canopy foliage in the western United States.

\begin{tabular}{|c|c|c|c|c|c|c|}
\hline \multirow[b]{2}{*}{ Year } & \multicolumn{2}{|c|}{$\begin{array}{l}\text { Emissions from } \\
\text { canopy fuels } \\
\left(\mathrm{Gg} \mathrm{yr}^{-1}\right)\end{array}$} & \multicolumn{2}{|c|}{$\begin{array}{c}\text { Emissions from } \\
\text { non-canopy fuels } \\
\left(\mathrm{Gg} \mathrm{yr}^{-1}\right)^{*}\end{array}$} & \multicolumn{2}{|c|}{$\begin{array}{c}\text { Canopy to } \\
\text { non-canopy } \\
\text { emission ratio }\end{array}$} \\
\hline & $\mathrm{CO}$ & $\mathrm{PM}_{2.5}$ & $\mathrm{CO}$ & $\mathrm{PM}_{2.5}$ & $\mathrm{CO}$ & $\mathrm{PM}_{2.5}$ \\
\hline 2003 & 228 & 35 & 2116 & 313 & 0.11 & 0.11 \\
\hline 2004 & 60 & 9 & 436 & 65 & 0.14 & 0.14 \\
\hline 2005 & 104 & 169 & 788 & 117 & 0.13 & 0.14 \\
\hline 2006 & 236 & 36 & 2084 & 302 & 0.11 & 0.12 \\
\hline 2007 & 387 & 59 & 3107 & 454 & 0.12 & 0.13 \\
\hline 2008 & 128 & 20 & 923 & 138 & 0.14 & 0.14 \\
\hline
\end{tabular}

* Emission data for non-canopy fuels is from Tables 4 and 5 .

\section{Supplementary material related to this article is available online at: http://www.atmos-chem-phys.net/11/12973/2011/ acp-11-12973-2011-supplement.zip.}

Acknowledgements. We thank Alex Petkov for assistance in the preparation of the MODIS data and Holly Eissinger and Rachel Corley for support creating publication quality maps. This research was supported by U.S. Forest Service Research and Development and U.S. Forest Service National Fire Plan. The views, opinions, and findings contained in these works are those of the authors and should not be interpreted as an official U.S. Forest Service or U.S. Government position, policy, or decision.

Edited by: B. N. Duncan

\section{References}

Akagi, S. K., Yokelson, R. J., Wiedinmyer, C., Alvarado, M. J., Reid, J. S., Karl, T., Crounse, J. D., and Wennberg, P. O.: Emission factors for open and domestic biomass burning for use in atmospheric models, Atmos. Chem. Phys., 11, 4039-4072, doi:10.5194/acp-11-4039-2011, 2011.

Albini, F. A.: Estimating wildfire behavior and effects, General Technical Report, INT-GTR-30, USDA Forest Service, Intermountain Forest and Range Experiment Station, Ogden Utah, 92 pp., available at: http://www.treesearch.fs.fed.us/pubs/29574, 1976.

Albini, F. A., Brown, J. K., Reinhardt, E. D., and Ottmar, R. D.: Calibration of a large fuel burnout model, Int. J. Wildland Fire, 5, 173-192, 1995.

Alvarado, M. J., Wang, C., and Prinn, R. G.: Formation of ozone and growth of aerosols in young smoke plumes from biomass burning: 2. Three-dimensional Eulerian studies, J. Geophys.Res., 114, D09307, doi:10.1029/2008JD011186, 2009.

Al-Saadi, J., Soja, A., Pierce, R. B., Szykman, J., Wiedinmyer, C., Emmons, L., Kondragunta, S., Zhang, X. Y., Kittaka, C., Schaack, T., and Bowman, K.: Intercomparison of near-real-time biomass burning emissions estimates constrained by satellite fire data, J. Appl. Remote. Sens., 2, doi:10.1117/1.2948785, 1-24, 2008.

Anderson, H. E.: Predicting wind-driven wildland fire size and shape, Research Paper INT-305, USDA Forest Service, Intermountain Forest and Range Experiment Station, Ogden, UT, 26 pp., 1983.

Brown, J. K., Marsden, M. M., Ryan, K. C., and Reinhardt, E. D.: Predicting duff and woody fuel consumed by prescribed fire in the northern Rocky Mountains, Research Paper INT-337, USDA, Intermountain Forest and Range Experiment Station Forest Service, 23 pp., available at: http://www.treesearch.fs.fed.us/pubs/ 32531, 1985.

Burling, I. R., Yokelson, R. J., Griffith, D. W. T., Johnson, T. J., Veres, P., Roberts, J. M., Warneke, C., Urbanski, S. P., Reardon, J., Weise, D. R., Hao, W. M., and de Gouw, J.: Laboratory measurements of trace gas emissions from biomass burning of fuel types from the southeastern and southwestern United States, Atmos. Chem. Phys., 10, 11115-11130, doi:10.5194/acp10-11115-2010, 2010

Carlson, J. D., Burgan, R. E., Engle, D. M., and Greenfield, J. R.: The Oklahoma Fire Danger Model: An operational tool for mesoscale fire danger rating in Oklahoma, Int. J. Wildland Fire, 11, 183-191, 2002.

Chang, D. and Song, Y.: Estimates of biomass burning emissions in tropical Asia based on satellite-derived data, Atmos. Chem. Phys., 10, 2335-2351, doi:10.5194/acp-10-2335-2010, 2010.

Clinton, N. E., Gong, P., and Scott, K.: Quantification of pollutants emitted from very large wildland fires in Southern California, USA, Atmos. Environ., 40, 3686-3695, 2006.

Cofer, W. R. III, Levine, J. S., Winstead, E. L., Lebel, P. J., Koller, A. M. Jr., and Hinkle, C. R.: Trace gas emissions from burning Florida wetlands, J. Geophys. Res., 101, 23597-23602, 1990.

Cohen, J. D. and Deeming, J. E.: The National Fire Danger Rating System: basic equations, Gen. tech. Rep. PSW-82, Pacific Southwest Forest and Range Experiment Station, Forest Service, U.S. Department of Agriculture, Berkeley, CA, 16 pp., available at: http://www.treesearch.fs.fed.us/pubs/27298, 1985.

DeBell, L. J., Talbot, R. W., Dibb, J. E., Munger, J. W., Fischer, E. V., and Frolking, S. E.: A major regional air pollution event in the northeastern United States caused by extensive forest fires in Quebec, Canada, J. Geophys. Res.-Atmos., 109, D19305, doi:10.1029/2004JD004840, 2004.

FOFEM 5.9, First Order Fire Effects Model software: http://www. firelab.org/science-applications/fire-fuel/111-fofem, last access: 2 May 2011.

French, N. H. F., Goovaerts, P., and Kasischke, E. S.: Uncertainty in estimating carbon emissions from boreal forest fires, J. Geophys. Res.-Atmos., 109, D14S08, doi:10.1029/2003JD003635 , 2004.

Friedli, H. R., Atlas, E., Stroud, V. R., Giovanni, L., Campos, T., and Radke, L. F.: Volatile organic trace gases emitted from North American wildfires, Global Biogeochem. Cy., 15, 435452, 2001.

Giglio, L., Descloitres, J., Justice, C. O., and Kaufman, Y. J.: An enhanced contextual fire detection algorithm for MODIS, Remote Sens. Environ., 87, 273-282, 2003.

Giglio, L., Loboda, T., Roy, D. P., Quayle, B., and Justice, C. O.: An active-fire based burned area mapping algorithm for the MODIS sensor, Remote Sens. Environ., 113, 408-420, 2009.

Giglio, L., Randerson, J. T., van der Werf, G. R., Kasibhatla, P. S., 
Collatz, G. J., Morton, D. C., and DeFries, R. S.: Assessing variability and long-term trends in burned area by merging multiple satellite fire products, Biogeosciences, 7, 1171-1186, 2010, http://www.biogeosciences.net/7/1171/2010/.

Hardy, C. C., Conard, S. G., Regelbrugge, J. C. and Teesdale, D. R.: Smoke emissions from prescribed burning of southern California chaparral, USDA Forest Service, Portland, OR., 1996.

Harrington, M. G.: Estimating ponderosa pine fuel moisture using national fire-danger rating fuel moisture values, USAD Forest Service Research Paper RM-233, Rocky Mountain Forest and Range Experiment Station, Fort Collins, CO, 7 pp., available at: http://www.fs.fed.us/rm/pubs_rm/rm_rn418.pdf, 1982.

Hoelzemann, J. J., Schultz, M. G., Brasseur, G. P., Granier, C., and Simon, M.: Global Wildland Fire Emission Model (GWEM): Evaluating the use of global area burnt satellite data, J. Geophys. Res.-Atmos., 109, D14S04, doi:10.1029/2003JD003666, 2004.

IPCC: 2006 Guidelines for National Greenhouse Gas Inventories, National Greenhouse Gas Inventories Programme, edited by: Eggleston, H. S., Buendia, L., Miwa, K., Ngara, T., and Tanabe, K., IGES, Japan, 3.1-3.66, 2006.

Ito, A. and Penner, J. E.: Estimates of $\mathrm{CO}$ emissions from open biomass burning in southern Africa for the year 2000, J. Geophys. Res.-Atmos., 110, D19306, doi:10.1029/2003JD004423, 2004.

Jain, A. K.: Global estimation of $\mathrm{CO}$ emissions using three sets of satellite data for burned area, Atmos. Environ., 41, 6931-6940, 2007.

JFSP, Joint Fire Science Program: http://www.firescience.gov/ index.cfm, last access: 5 May 2011, 2008.

LANDFIRE, LANDFIRE Project, U.S. Department of Interior, Geological Survey: http://www.landfire.gov/, last access: 2 May $2011 \mathrm{a}, 2011$.

LANDFIRE, The LANDFIRE data distribution site, U.S. Department of Interior, Geological Survey: http://landfire.cr.usgs.gov/ viewer/, last access: 2 May 2011b, 2011.

Langmann, B., Duncan, B., Textor, C., Trentmann, J., and van der Werf, G. R.: Vegetation fire emissions and their impact on air pollution and climate, Atmos. Environ., 43, 107-116, 2009.

Lapina, K., Honrath, R. E., Owen, R. C., Martin, M. V., and Pfister, G.: Evidence of significant large-scale impacts of boreal fires on ozone levels in the midlatitude Northern Hemisphere free troposphere, Geophys. Res. Lett., 33, L10815, doi:10.1029/2006GL025878, 2006.

Larkin, N. K., O’Neill, S. M., Solomon, R., Raffuse, S., Strand, T., Sullivan, D. C., Krull, C., Rorig, M., Peterson, J. L., and Ferguson, S. A.: The BlueSky smoke modeling framework, Int. J. Wildland Fire, 18, 906-920, 2009.

Li, R. R., Kaufman, Y. J., Hao, H. M., Salmon, J. M., and Gao, B. C.: A technique for detecting burn scars using MODIS data, IEEE T. Geosci. Remote., 42, 1300-1308, 2004.

Liousse, C., Guillaume, B., Grégoire, J. M., Mallet, M., Galy, C., Pont, V., Akpo, A., Bedou, M., Castéra, P., Dungall, L., Gardrat, E., Granier, C., Konar, A., Malavelle, F., Mariscal, A., Mieville, A., Rosset, R., Sera, D., Solmon, F., Tummon, F., Assamoi, E., Yobou, V., and Van Velthoven, P.: Updated African biomass burning emission inventories in the framework of the AMMAIDAF program, with an evaluation of combustion aerosols, Atmos. Chem. Phys., 10, 9631-9646, doi:10.5194/acp-10-96312010, 2010.
Liu, Y. Q., Goodrick, S., Achtemeier, G., Jackson, W. A., Qu, J. J., and Wang, W. T.: Smoke incursions into urban areas: simulation of a Georgia prescribed burn, Int. J. Wildland Fire, 18, 336-348, 2009.

Lutes, D. C., Keane, R. E., and Caratti, J. F.: A surface fuel classification for estimating fire effects, Int. J. Wildland Fire, 18, 802814, 2009.

Mesinger, F., DiMego, G., Kalnay, E., Mitchell, K., Shafran, P. C., Ebisuzaki, W., Jovic, D., Woollen, J., Rogers, E., Berbery, E. H., Ek, M. B., Fan, Y., Grumbine, R., Higgins, W., Li, H., Lin, Y., Manikin, G., Parrish, D., and Shi, W.: North American regional reanalysis, B. Am. Meteorol. Soc., 87, 343-360, 2006.

Michel, C., Liousse, C., Gregoire, J. M., Tansey, K., Carmichael, G. R., and Woo, J. H.: Biomass burning emission inventory from burnt area data given by the SPOT-VEGETATION system in the frame of TRACE-P and ACE-Asia campaigns, J. Geophys. Res.Atmos., 110, D09304, doi:10.1029/2004JD005461 , 2005.

Mieville, A., Granier, C., Liousse, C., Guillaume, B., Mouillot, F., Lamarque, J. F., Gregoire, J. M., and Petron, G.: Emissions of gases and particles from biomass burning during the 20th century using satellite data and an historical reconstruction, Atmos. Environ., 44, 1469-1477, 2010.

MTBS, Data Access: Burned Area Boundaries Data: http:// mtbs.gov/compositfire/mosaic/bin-release/burnedarea.html, last access: 3 May 2011a, 2011.

MTBS, Data Access: Regional MTBS Burn Severity Mosaics: http: //mtbs.gov/compositfire/mosaic/bin-release/download.html, last access: 3 May 2011b, 2011.

MTBS, Monitoring trends in Burn Severity: http://mtbs.gov/index. html, last access: 3 May 2011c, 2011.

Morris, G. A., Hersey, S., Thompson, A. M., Pawson, S., Nielsen, J. E., Colarco, P. R., McMillan, W. W., Stohl, A., Turquety, S., Warner, J., Johnson, B. J., Kucsera, T. L., Larko, D. E., Oltmans, S. J., and Witte, J. C.: Alaskan and Canadian forest fires exacerbate ozone pollution over Houston, Texas, on 19 and 20 July 2004, J. Geophys. Res.-Atmos., 111, D24S03, doi:10.1029/2006JD007090, 2006.

Muhle, J., Lueker, T. J., Su, Y., Miller, B. R., Prather, K. A., and Weiss, R. F.: Trace gas and particulate emissions from the 2003 southern California wildfires, J. Geophys. Res.-Atmos., 112, D03307, doi:10.1029/2006JD007350, 2007.

Nance, J. D., Hobbs, P. V., and Radke, L. F.: airborne measurements of gases and particles from an alaskan wildfire, J. Geophys. Res.Atmos., 98, 14873-14882, 1993.

NASA: MODIS L1 and Atmospheres Archive and Distribution System (LAADS), NASA: http://ladsweb.nascom.nasa.gov/, last access: 2 May 2011.

National Interagency Coordination Center, Incident Management Situation Report Archives: http://www.predictiveservices.nifc. gov/intelligence/archive.htm, last access: 2 May 2011.

Natural Fuels Photo Series: http://www.fs.fed.us/pnw/fera/ research/fuels/photo_series/index.shtml, last access: 1 May 2011, 2011.

Natural Fuels Digital Photo Series, Volume XI: Pacific Northwest II, Eastern Oregon Sagebrush with Grass: http://depts. washington.edu/nwfire/dps/, last access: 1 May 2011, 2011.

Ottmar, R. D., Vihnanek, Robert E., and Wright, C. S.: Stereo photo series for quantifying natural fuels: volume I: Mixed-conifer with mortality, western juniper, sagebrush, and grassland types 
in the interior Pacific Northwest: PMS 830. NFES 2580, Boise, Idaho: National Wildfire Coordinating Group, National Interagency Fire Center, 73 pp., Digital Photo Series available at: http://depts.washington.edu/nwfire/dps/, 1998.

Ottmar, R. D., Vihnanek, R. E., Wright, and C. S.: Stereo photo series for quantifying natural fuels. Volume III: Lodgepole pine, quaking aspen, and gambel oak types in the Rocky Mountains: PMS 832, Boise, ID: National Wildfire Coordinating Group, National Interagency Fire Center, 85 pp., Digital Photo Series available at: http://depts.washington.edu/nwfire/dps/, 2000a.

Ottmar, R. D., Vihnanek, R. E., and Regelbrugge, J. C.: Stereo photo series for quantifying natural fuels. Volume IV: pinyonjuniper, sagebrush, and chaparral types in the Southwestern United States: PMS 833, Boise, ID: National Wildfire Coordinating Group, National Interagency Fire Center, 97 pp., Digital Photo Series available at: http://depts.washington.edu/nwfire/ dps/, 2000b.

Ottmar, R. D., Vihnanek, R. E., Wright, C. S., and Olson, D. L, Stereo photo series for quantifying natural fuels. Volume VII: Oregon white oak, California deciduous oak, and mixed-conifer with shrub types in the Western United States: PMS 839, Boise, ID: National Wildfire Coordinating Group, National Interagency Fire Center, 75 pp., Digital Photo Series available at: http://depts. washington.edu/nwfire/dps/, 2004.

Ottmar, R. D., Sandberg, D. V., Riccardi, C. L., and Prichard, S. J.: An overview of the Fuel Characteristic Classification System Quantifying, classifying, and creating fuelbeds for resource planning, Can. J. Forest. Res., 37, 2383-2393, 2007a.

Ottmar, R. D., Vihnanek, R. E., and Wright, C. S.: Stereo photo series for quantifying natural fuels: volume X: Sagebrush with grass and ponderosa pine-juniper types in central Montana, Gen. Tech. Rep. PNW-GTR-719, U.S. Department of Agriculture, Forest Service, Pacific Northwest Research Station, 59 pp., Digital Photo Series available at: http://depts.washington.edu/nwfire/ dps/, 2007b.

Park, R. J., Jacob, D. J., and Logan, J. A.: Fire and biofuel contributions to annual mean aerosol mass concentrations in the United States, Atmos. Enviorn., 41, 7389-7400, doi:10.1016/j.atmosenv.2007.05.061, 2007.

Pfister, G., Emmons, L., and Wiedinmyer, C.: Impacts of the fall 2007 California wildfires on surface ozone: integrating local observations with global model simulations, Geophys. Res.Lett., 35, L19814, doi:10.1029/2007JD008797, 2008.

Phuleria, H. C., Fine, P. M., Zhu, Y. F., and Sioutas, C.: Air quality impacts of the October 2003 Southern California wildfires, J. Geophys. Res.-Atmos., 110, D07S20, doi:10.1029/2004JD004626, 2005.

Prichard, S .J., Ottmar, R. D., and Anderson, G. K.: Consume 3.0 user's guide, Pacific Northwest Research Station, Corvallis, Oregon, 234 pp., available at: http://www.firelab.org/ science-applications/fire-fuel/111-fofem, 2006.

Radke, L. F., Hegg, D. A., Hobbs, P. V., Nance, J. D., Lyons, J. H., Laursen, K. K., Weiss, R. E., Riggan, P. J., and Ward, D. E.: Particulate and trace gas emissions from large biomass fires in North America, in Global Biomass Burning: Atmospheric, Climatic, and Biospheric Implications, edited by: Levine, J. S., 209-224, MIT Press, Cambridge, MA, 1991.

Reid, J. S., Hyer, E. J., Prins, E. M., Westphal, D. L., Zhang, J. L., Wang, J., Christopher, S. A., Curtis, C. A., Schmidt, C. C., Eleu- terio, D. P., Richardson, K. A., and Hoffman, J. P.: Global Monitoring and Forecasting of Biomass-Burning Smoke: Description of and Lessons From the Fire Locating and Modeling of Burning Emissions (FLAMBE) Program, IEEE J. Sel. Top. Appl., 2, 144-162, 2009.

Reinhardt, E. D. : Using FOFEM5.0 to estimate tree mortality, fuel consumption, smoke production and soil heating from wildland fire, in: Proceedings of the Second International Wildland Fire Ecology and Fire Management Congress and Fifth Symposium on Fire and Forest Meteorology, American Meteorological Society, Orlando, Florida, 16-20 November 2003, available at: http:// www.firelab.org/science-applications/fire-fuel/111-fofem, 2003.

Rothermel, R.C.: A mathematical model for predicting fire spread in wildland fuels, Res. Pap. INT-115, USDA Forest Service, Intermountain Forest and Range Experiment Station, 40 pp., 1972.

Sapkota, A., Symons, J. M., Kleissl, J., Wang, L., Parlange, M. B., Ondov, J., Breysse, P. N., Diette, G. B., Eggleston, P. A., and Buckley, T.J.: Impact of the 2002 Canadian Forest Fires on Particulate Matter Air Quality in Baltimore City, Environ. Sci. Technol., 39, 24-32, 2005.

Schwind, B.: Monitoring trends in burn severity: report on the PNW \& PSW fires - 1984 to 2005, MTBS Project Team, U.S. Geologiocal Survey and U.S. Forest Service, Remote Sensing Applications Center, Salt Lake City, Utah, 2008.

Seiler, W. and Crutzen, P. J.: Estimates of gross and net fluxes of carbon between the biosphere and the atmosphere from biomass burning, Climatic Change, 2, 207-247, 1980.

Simpson, I. J., Rowland, F. S., Meinardi, S., and Blake, D. R.: Influence of biomass burning during recent fluctuations in the slow growth of global tropospheric methane, Geophys. Res. Lett., 33, L22808, doi:10.1029/2006GL027330, 2006.

Sikkink, P. G., Lutes, D. C., and Keane, R. E.: Field guide for identifying fuel loading models, Gen. Tech. Rep. RMRS-GTR-225, USDA, Forest Service, Rocky Mountain Research Station, Fort Collins, Colorado, 33 pp., 2009.

Soja, A. J., Cofer, W. R., Shugart, H. H., Sukhinin, A. I., Stackhouse, P. W., McRae, D. J., and Conard, S. G.: Estimating fire emissions and disparities in boreal Siberia (1998-2002), J. Geophys. Res.-Atmos., 109, D14S06, doi:10.1029/2004JD004570, 2004.

Spracklen, D. V., Logan, J. A., Mickley, L. J., Park, R. J., Yevich, R., Westerling, A. L., and Jaffe, D. A.: Wildfires drive interannual variability of organic carbon aerosol in the western U.S. in summer, GeophyS. Res. Lett., 34, L16816, doi:10.1029/2007GL030037, 2007.

Stroppiana, D., Brivio, P. A., Grégoire, J.-M., Liousse, C., Guillaume, B., Granier, C., Mieville, A., Chin, M., and Pétron, G.: Comparison of global inventories of $\mathrm{CO}$ emissions from biomass burning derived from remotely sensed data, Atmos. Chem. Phys., 10, 12173-12189, doi:10.5194/acp-10-12173-2010, 2010.

Sudo, K. and Akimoto, H.: Global source attribution of tropospheric ozone: long-range transport from various source regions, J. Geophys. Res., 112, D12302, doi:10.1029/2006JD007992 , 2007

USEPA, Emission Inventories: http://www.epa.gov/ttn/chief/ eiinformation.html, last access: 2 May 2011, 2011.

Urbanski, S. P., Salmon, J. M., Nordgren, B. L., and Hao, W. M.: A MODIS direct broadcast algorithm for mapping wildfire burned area in the western United States, Remote Sens. Environ., 113, 
2511-2526, 2009a.

Urbanski, S. P., Hao, W. M., and Baker, S.: Chemical composition of Wildland Fire Emissions, in: Developments in Environmental Science, 8, edited by: Bytnerowicz, A. Arbaugh, M., Riebau, A., and Andersen, C., Elsevier, The Netherlands, 79-107, $2009 \mathrm{~b}$.

van der Werf, G. R., Randerson, J. T., Giglio, L., Collatz, G. J., Kasibhatla, P. S., and Arellano Jr., A. F.: Interannual variability in global biomass burning emissions from 1997 to 2004, Atmos. Chem. Phys., 6, 3423-3441, doi:10.5194/acp-6-3423-2006, 2006.

van der Werf, G. R., Randerson, J. T., Giglio, L., Collatz, G. J., Mu, M., Kasibhatla, P. S., Morton, D. C., DeFries, R. S., Jin, Y., and van Leeuwen, T. T.: Global fire emissions and the contribution of deforestation, savanna, forest, agricultural, and peat fires (19972009), Atmos. Chem. Phys., 10, 11707-11735, doi:10.5194/acp10-11707-2010, 2010.

Wiedinmyer, C., Quayle, B., Geron, C., Belote, A., McKenzie, D., Zhang, X. Y., O'Neill, S., and Wynne, K. K.: Estimating emissions from fires in North America for air quality modeling, Atmos. Environ., 40, 3419-3432, 2006.
Wiedinmyer, C., Akagi, S. K., Yokelson, R. J., Emmons, L. K., AlSaadi, J. A., Orlando, J. J., and Soja, A. J.: The Fire INventory from NCAR (FINN) - a high resolution global model to estimate the emissions from open burning, Geosci. Model Dev., 4, 625641, 2011.

Wilcox, R. R.: A note on the Theil-Sen regression estimator when the regressor is random and the error term is heteroscedastic, Biometrical J., 40, 261-268, 1998.

Wilcox, R. R.: Introduction to robust estimation and hypothesis testing, Elsevier Academic Press, Burlington, MA, 413-464, 2005.

Yokelson, R. J., Goode, J. G., Ward, D. E., Susott, R. A., Babbitt, R. E., Wade, D. D., Bertschi, I., Griffith, D. W. T., and Hao, W. M.: Emissions of formaldehyde, acetic acid, methanol, and other trace gases from biomass fires in North Carolina measured by airborne Fourier transform infrared spectroscopy, J. Geophys. Res.-Atmos., 104, 30109-30125, 1999.

Zhang, X. Y., Kondragunta, S., Schmidt, C., and Kogan, F.: Near real time monitoring of biomass burning particulate emissions $\left(\mathrm{PM}_{2.5}\right)$ across contiguous United States using multiple satellite instruments, Atmos. Environ., 42, 6959-6972, 2008. 